\title{
Therapeutic strategies against cancer stem cells in human colorectal cancer (Review)
}

\author{
MAGDALENA SZARYŃSKA ${ }^{1}$, AGATA OLEJNICZAK ${ }^{1}$, JAROSŁAW KOBIELA ${ }^{2}$, \\ PIOTR SPYCHALSKI ${ }^{2}$ and ZBIGNIEW KMIEĆ ${ }^{1}$ \\ ${ }^{1}$ Department of Histology, Medical University of Gdańsk, 80-210 Gdańsk; ${ }^{2}$ Department of General, Endocrine \\ and Transplant Surgery, Invasive Medicine Center, Medical University of Gdańsk, 80-214 Gdańsk, Poland
}

Received April 19, 2017; Accepted September 1, 2017

DOI: $10.3892 / \mathrm{ol} .2017 .7261$

\begin{abstract}
Colorectal cancer (CRC) is the third most frequent malignancy and represents the fourth most common cause of cancer-associated mortalities in the world. Despite many advances in the treatment of $\mathrm{CRC}$, the 5-year survival rate of patients with CRC remains unsatisfactory due to tumor recurrence and metastases. Recently, cancer stem cells (CSCs), have been suggested to be responsible for the initiation and relapse of the disease, and have been identified in CRC. Due to their basic biological features, which include self-renewal and pluripotency,
\end{abstract}

Correspondence to: Dr Magdalena Szaryńska, Department of Histology, Medical University of Gdańsk, 1 Dębinki, 80-210 Gdańsk, Poland

E-mail: mszarynska@gumed.edu.pl

Abbreviations: 5-FU, 5-fluorouracil; AKT, protein kinase B; ALDH-1, aldehyde dehydrogenase 1; AMPK, energy rheostat AMP-activated protein kinase; APC, adenomatous polyposis coli; BMP4, bone morphogenetic protein 4; CBP, cyclic AMP response element binding protein; CK1, casein kinase 1; Chk2, check point kinase 2; COX-1/2, cyclooxygenase 1/2; CRC, colorectal cancer; CSC, cancer stem cell; Dkk1, Dickkopf-1; DLL4, delta-Like 4 ligand; EGF, epidermal growth factor; EGFR, epidermal growth factor receptor; EMT, epithelial-mesenchymal transition; GSK-3 $\beta$, glycogen synthase kinase $3 \beta ;$ IGF-1/2, insulin-like growth factor 1/2; IGFR, insulin-like growth factor-1 receptor; Mcl-1, myeloid cell leukemia 1; MET, metformin; NICD, notch intracellular domain; NSAIDs, non-steroidal anti-inflammatory drugs; PAK1, p21-activated kinase 1; PI3K, phosphatidylinositol-4,5-bisphosphate 3-kinase; PPAR $\gamma$, peroxisome proliferator-activated receptors; RTKs, receptors tyrosine kinases; RYK, receptor-like tyrosine kinase; shRNA, small hairpin RNA; siRNA, small interfering RNA; SIRT1, silent mating type information regulation 2 homolog 1; SMAD3, SMAD family member 3; STAT3, signal transducer and activator of transcription 3; TCF/LEF, T-cell factor/lymphoid enhancer factor; TERT, telomerase reverse transcriptase; TGF $\beta$, transforming growth factor $\beta$; Tnk, tankyrase; TRAIL, tumor necrosis factor related apoptosis-inducing ligand; VEGF, vascular endothelial growth factor

Key words: colorectal cancer, cancer stem cells, chemoresistance reduction, apoptosis induction
CSCs may be novel therapeutic targets for CRC and other cancer types. Conventional therapeutics only act on proliferating and mature cancer cells, while quiescent CSCs survive and often become resistant to chemotherapy. In this review, markers of CRC-CSCs are evaluated and the recently introduced experimental therapies that specifically target these cells by inducing CSC proliferation, differentiation and sensitization to apoptotic signals via molecules including Dickkopf-1, bone morphogenetic protein 4, Kindlin-1, tankyrases, and p21-activated kinase 1, are discussed. In addition, novel strategies aimed at inhibiting some crucial processes engaged in cancer progression regulated by the Wnt, transforming growth factor $\beta$ and Notch signaling pathways (pyrvinium pamoate, silibinin, PRI-724, P17, and P144 peptides) are also evaluated. Although the metabolic alterations in cancer were first described decades ago, it is only recently that the concept of targeting key regulatory molecules of cell metabolism, such as sirtuin 1 (miR-34a) and AMPK (metformin), has emerged. In conclusion, the discovery of CSCs has resulted in the definition of novel therapeutic targets and the development of novel experimental therapies for CRC. However, further investigations are required in order to apply these novel drugs in human CRC.

\section{Contents}

1. Introduction

2. Identification of cancer stem cells in colorectal cancer

3. The characteristics of CRC-CSCs being considered for CSC-targeting therapeutic strategies

4. Crucial signaling pathways associated with efficient maintenance of CRC-CSCs: Potential targets for therapy of CRC-CSC

5. Metabolic target strategy

6. Chemoprevention: Nonsteroid anti-inflammatory drugs in CRC therapy

7. Conclusions

\section{Introduction}

Colorectal cancer (CRC) is one of the most common malignancies and a major cause of cancer-related death worldwide. 
It is the second most common type of cancer in both genders (women: $10.1 \%$; men: $12.4 \%$ ) and the number of newly diagnosed CRC cases continues to grow. CRC, according to the WHO, is the third most common cancer, with 1,361,000 cases worldwide in 2012 (1).

The primary treatment of CRC is surgical resection. However, approximately $25 \%$ of CRC cases are detected in stage IV (with distant metastases) and almost $50 \%$ of CRC patients will develop metastasis during their lifetime (2). The treatment outcomes for these patients are unfavorable, since conventional therapies affect proliferating and differentiated cancer cells from the tumor mass and save cancer stem cells (CSCs). This approach seems to explain the initial post-therapy tumor shrinkage, which is often followed by relapses resulting from the activity of CSCs (3).

Chemotherapy of patients with CRC can be performed either as monotherapy (capecitabine, irinotecan) or with a combined protocol (4-6): LVFU2: 5-fluorouracil $(5-\mathrm{FU})+$ calcium folinate racemate (or levofolinic acid in equivalent dose); FOLFOX4: 5-FU + calcium folinate racemate (or levofolinic acid in equivalent dose) + oxaliplatin; FOLFOXIRI: 5-FU + calcium folinate racemate (or levofolinic acid in equivalent dose) + oxaliplatin + irinotecan; FOLFIRI: 5-FU + calcium folinate racemate (or levofolinic acid in equivalent dose) + irinotecan; CAPOX (XELOX): Capecitabine + oxaliplatin.

Presurgical radiotherapy can be included in two different ways. The first involves five fractions of radiotherapy (5 Gy) each a week before surgical intervention. The second therapeutic mode involves a total of 50.0-50.4 Gy divided into 1.8 or 2.0 Gy fractions, combined with chemotherapy using fluorouracil, either with calcium folinate or with capecitabine. In the second protocol, surgery is delayed and is performed at least six weeks after the last course of radiotherapy. Both protocols ensure similar efficacy $(7,8)$.

Additionally, in recent years, new drugs targeting growth factors or their surface receptors have been introduced as additional therapy for the treatment of CRC (Table I).

Although about $50 \%$ of patients respond to conventional therapy, most develop drug resistance during the course of treatment, and recurrence of the disease often follows $(9,10)$. Our review presents the current state of knowledge concerning experimental CRC treatment protocols targeting CSCs through the induction of their proliferation, differentiation, and sensitization to apoptotic signals. The combined therapy consisting of two distinct constituents: Conventional drugs and the novel anti-CSC factor; an improvement of the anticancer therapy efficacy and a reduction in undesirable side effects is hoped for.

\section{Identification of cancer stem cells in colorectal cancer}

Under physiological conditions, the pool of normal cells is maintained in tissues and organs due to the presence of small subpopulation of stem cells with a great capability to self-renew, proliferate, and differentiate. A tumor can be seen as an abnormal type of tissue whose growth and development are depend on a population of stem cells, termed CSCs (11-13). These CSCs may gain their specific properties-such as self-renewal, unlimited proliferation potential, and ability to differentiate into any mature cancer cell type-as a result of neoplastic transformation caused by the accumulation of some genetic and epigenetic aberrations. Additionally, they develop specific protective mechanisms, such as those directed against immune cells, or insensitivity to standard chemotherapeutics. The CSC hypothesis remains controversial, but the occurrence of CSCs has been identified within both hematological and solid tumors, such as breast and CRCs (11-13).

The identification of CRC-CSCs is based on a set of CSC-associated protein markers (Table II). It is not clear if all of these biomarkers influence CRC progression with the same effect. Furthermore, the great range of these proteins may result from the genetic heterogeneity of cancer cells both within the tumors of a particular patient and between patients $(11,14,15)$. Experimental data from the rodent model of CRC suggest that only 1 in 25 cells $(16)$, or 1 in 262 cells $(13,16)$, possesses the characteristic features of CSCs in the total population of CRC cells. This diversity may result from the complexity of experimental settings. The initial verification of new markers for the isolation of CSCs often follows discoveries in the field concerning either normal tissue stem cells or CSCs of different tumors. However, the selection of the most universal and useful CSCs markers has yet to be performed.

A minor Bmi-1-positive subpopulation of CSCs is characterized by low mitotic activity, and thus is supposed to constitute the pool of cells which are resistant to chemotherapeutics and responsible for tumor relapse through intense proliferation following therapy $(17,18)$. According to the CSC hypothesis, conventional chemotherapeutics reduce the tumor mass, but are not sufficiently efficient to eliminate all cancer cells, on account of the presence of chemoresistant CSCs. Efficient DNA repair mechanisms, telomerase activity, insensitivity to proapoptotic signals, and high levels of expression of ATP-binding cassette transporters (ABC transporters) are postulated as the main causes of chemoresistance (19-21).

CD133 protein. The identification and classification of CSCs is rather controversial, as none of the known markers are universal and reliable for the identification of CSCs in all experimental settings (Table II) (22). The most commonly used marker of CRC-CSCs is prominin-1, also named CD133 (22). CD133+ cells are able to reproduce a CRC tumor in a mouse xenotransplantation model, whereas CD133- cells cannot rebuild cancer bulk $(11,13)$. However, the research groups of Ricci-Vittani and Shmelkov showed independently that CD133- cells also possess high proliferative and differentiating potential, comparable to those of CD133 ${ }^{+}$CRC-CSCs $(13,14)$. CD133 ${ }^{+}$CRC-CSCs isolated from human tumors may be cultured in vitro for as long as one year without any change in their phenotype, gaining the ability to form undifferentiated tumor spheres which maintain the ability to engraft (13). Moreover, it has been shown that even a single $\mathrm{CD}_{133^{+}}$cell is able to reproduce the tumor mass in vivo (23). Human CRCs resistant to a conventional 5-FU treatment have been found to be enriched in $\mathrm{CD}_{133^{+}}$cells; this is directly correlated with a worse outcome for patients (24). However, knockout of CD133 has been found not to affect the clonogenicity of cancer cells, suggesting that CD133 is a passive marker, rather than a CSC-promoting factor (25-27).

CD44 protein. CD44 is a transmembrane glycoprotein, a receptor of hyaluronic acid that participates in many cellular 


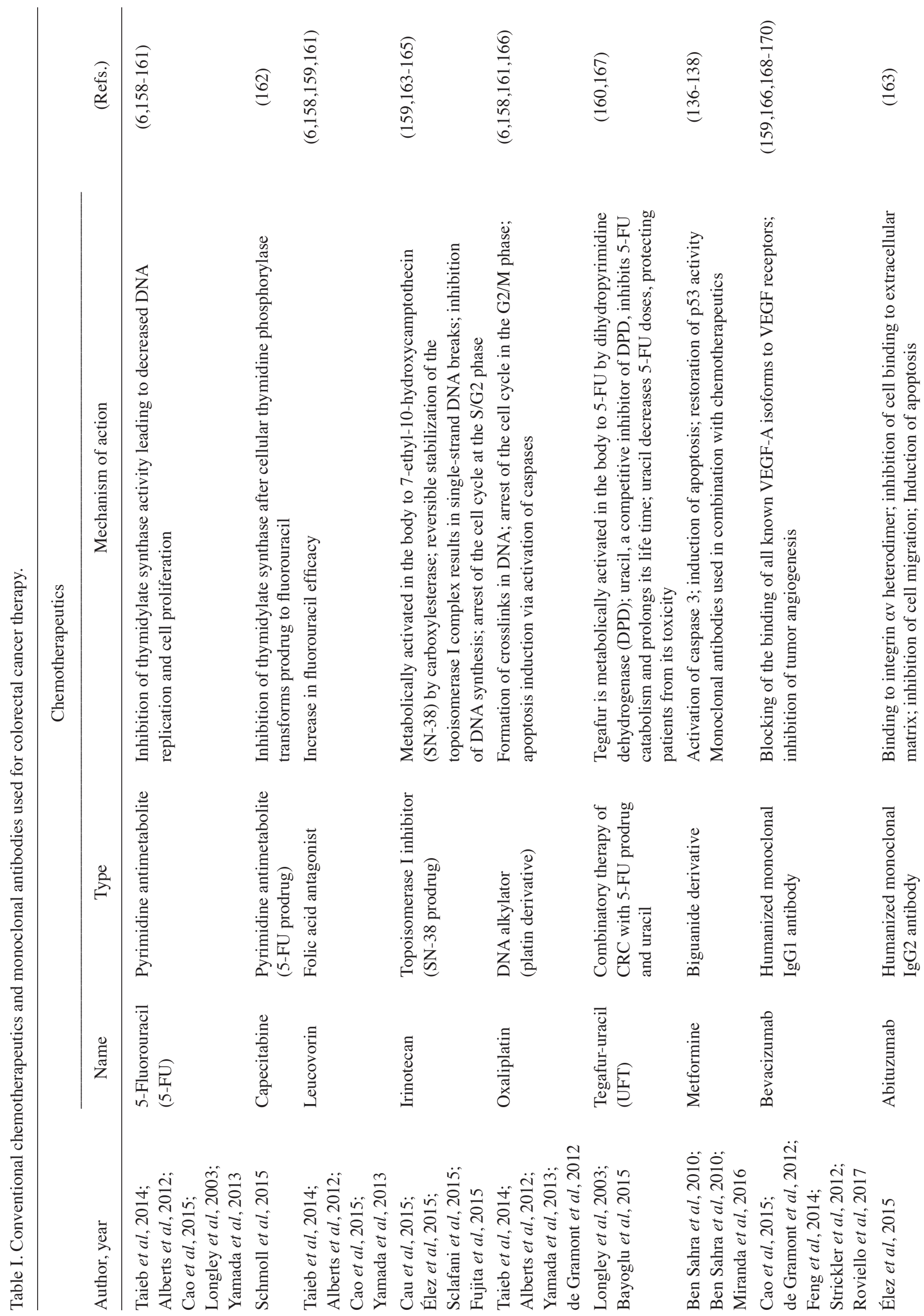




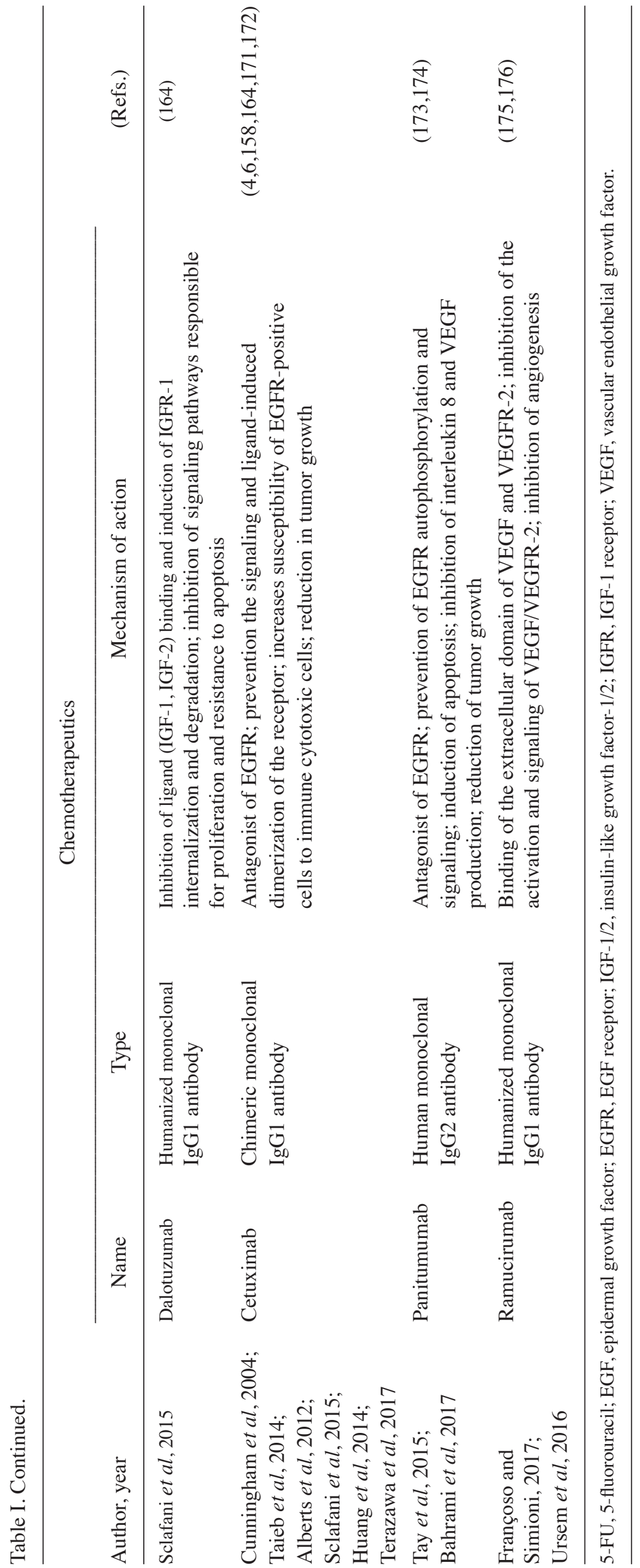


Table II. Markers of colorectal cancer stem cells.

\begin{tabular}{|c|c|c|c|}
\hline Author, year & Marker & Function & (Refs.) \\
\hline $\begin{array}{l}\text { Ricci-Vitiani et al, 2007; } \\
\text { Botchkina, 2013; } \\
\text { Haraguchi et al, 2008; } \\
\text { Zhu et al, } 2009\end{array}$ & CD133 & $\begin{array}{l}\text { Prominin-1; membrane glycoprotein, present on } \\
\text { the surface of actively proliferating stem cells; } \\
\text { function unknown }\end{array}$ & $(13,177-179)$ \\
\hline $\begin{array}{l}\text { Manhas et al, 2016; } \\
\text { Vermeulen } \text { et al, 2008; } \\
\text { Du et al, 2008; } \\
\text { Haraguchi et al, 2008; } \\
\text { Botchkina } \text { et al, } 2009\end{array}$ & CD44 & P Glycoprotein 1; membrane hyaluronic acid receptor & $(2,23,26,178,180)$ \\
\hline $\begin{array}{l}\text { Manhas et al, } 2016 \text {; } \\
\text { Vermeulen et al, } 2008 \\
\text { Botchkina } \text { et al, } 2009\end{array}$ & CD166 & ALCAM; membrane glycoprotein, adhesion molecule & $(2,23,180)$ \\
\hline $\begin{array}{l}\text { Huang et al, 2009; } \\
\text { Zhou et al, } 2015\end{array}$ & ALDH1 & $\begin{array}{l}\text { Aldehyde dehydrogenase, detoxification enzyme, transforms } \\
\text { retinol to retinoic acid, which regulates proliferation of cells }\end{array}$ & $(16,181)$ \\
\hline Vermeulen et al, 2008 & CD29 & $\beta 1$ integrin, adhesion molecule & (23) \\
\hline $\begin{array}{l}\text { Manhas et al, 2016; } \\
\text { Vermeulen et al, } 2008\end{array}$ & $\mathrm{CD} 24$ & $\begin{array}{l}\text { Heat-stable antigen; membrane glycoprotein, } \\
\text { adhesion molecule }\end{array}$ & $(2,23)$ \\
\hline Manhas et al, 2016 & ESA & $\begin{array}{l}\text { Epithelial specific antigen, EpCAM, CD326; membrane } \\
\text { glycoprotein, adhesion and signaling molecule; }\end{array}$ & (2) \\
\hline
\end{tabular}

ALDH1, aldehyde dehydrogenase 1; ESA, epithelial-specific antigen; ALCAM, activated leukocyte cell adhesion molecule; EpCAM, epithelial cell adhesion molecule.

processes, including growth, survival, differentiation and motility. $\mathrm{CD}_{4} 4^{+} \mathrm{CD} 133^{-}$cells isolated from human $\mathrm{CRC}$ tumors have been shown in vivo to efficiently initiate a xenograft tumor that possesses similar properties to those of the primary tumor. Knockdown of CD44 strongly reduced proliferation of these cells and inhibited tumorigenicity in a mouse xenograft model $(26,27)$.

Aldehyde dehydrogenase 1. Aldehyde dehydrogenase 1 (ALDH-1) has been identified in both nonmalignant and malignant stem cells. In many neoplasms-such as colon, pancreas, breast, and urinary bladder cancers-this enzyme has been shown to be associated with disease progression (16,28-31). Generally, ALDH-1 is responsible for detoxification and defending against free radicals, although it plays a crucial function in cancer recurrence due to the downregulation of CSCs' metabolism during conventional chemotherapy (16,28-31). The activity of ALDH-1 may be pharmacologically blocked via the specific inhibitor DAEB (diethylaminobenzaldehyde) (30). A combination of DAEB with conventional chemotherapeutics, such as doxorubicin and paclitaxel, increases the level of oxidative stress in cells, enhancing their susceptibility to free radicals and apoptosis. The first promising results of such an approach were demonstrated for breast cancer cell lines (32).

\section{The characteristics of CRC-CSCs being considered for CSC-targeting therapeutic strategies}

The discovery of CSCs in various tumors has provided new opportunities to overcome chemoresistance and radioresistance of tumor cells through the targeting of this unique population (Fig. 1). To achieve this goal, diverse strategies have been used: the induction of CSC differentiation, the inhibition of the epithelial-mesenchymal transition (EMT), the reduction of angiogenesis, and the suppression of specific signaling or metabolic pathways. Significantly, our increasing understanding of the cellular and molecular mechanisms that regulate CSC quiescence, cell cycle progression, self-renewal, and resistance to proapoptotic signals and chemotherapeutics may provide new therapeutic modalities that will reduce morbidity and increase the overall survival of CRC patients.

Induction of CRC-CSC differentiation. The first of the therapeutic approaches is based on the induction of CSC differentiation into more mature types of tumor cells, resulting in a reduction of $\mathrm{CSC}$ number. In contrast to $\mathrm{CSC}$, mature cancer cells have no self-renewal ability, cannot proliferate unlimitedly or induce immunological tolerance, and are more susceptible to conventional chemotherapy. Such a therapeutic strategy has been already used in promyelocytic leukemia patients being treated by retinoic acid (RA). Increased intracellular RA concentration upregulates the expression of its normal retinoic acid receptor, RAR, which competitively displaces the cancer-mutated receptor, PML-RAR. RA functions as an agonist of steroid hormone receptors and, due to the binding to transcription factors in the nucleus, may induce the differentiation of abnormal blasts (33).

Impairment of cell cycle checkpoints in CRC-CSCs. Blocking of the cell cycle checkpoint proteins represents a novel 


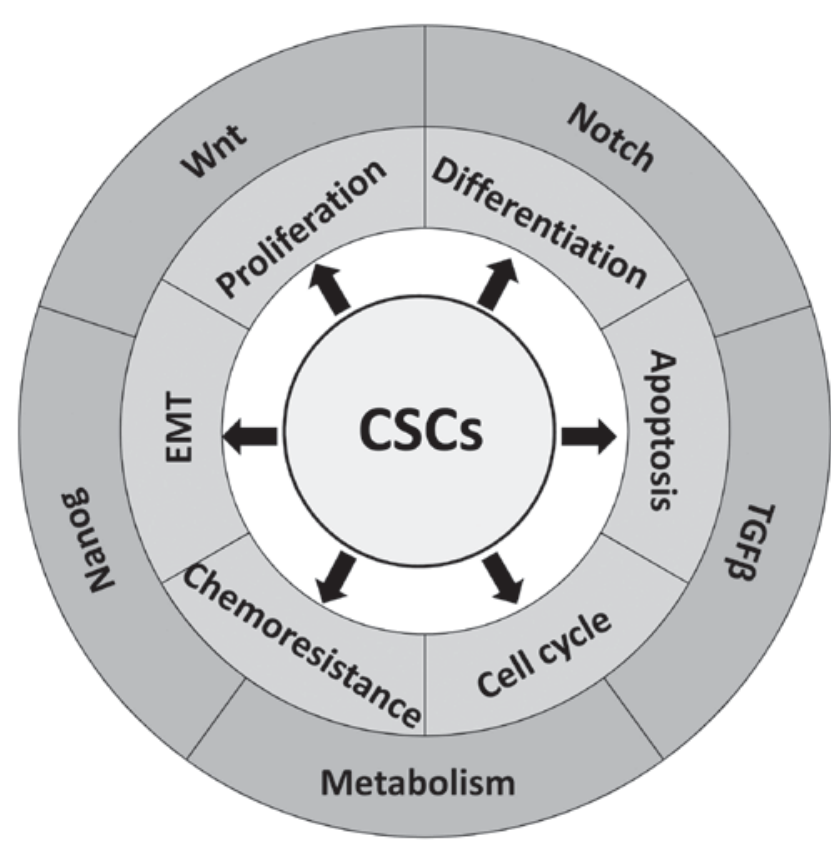

Figure 1. The features characteristic for CRC-CSCs and crucial signaling pathways which are under consideration in regards to CSC-targeting therapeutic strategies. CRC, colorectal cancer; CSC, cancer stem cell.

approach to treatment aimed at overcoming CSC resistance to conventional cancer therapy. This approach is based on the assumption that cells with dysfunctional checkpoints proliferate in an uncontrolled manner, which could cause genome and metabolic destabilization and lead to cell death.

The combination of two potential therapeutic compounds, flavonoid morin and telomerase inhibitor MST-312, has been demonstrated to lower tumorigenicity of CSCs by targeting signal transducer and activator of transcription 3 (STAT3) and telomerase in human CRC cells. A morin/MST-312 combination has been shown to inhibit the phosphorylation of cellular proteins such as p53 and check point kinase 2 (Chk2), which are known to play crucial roles in DNA damage checkpoint control. Inhibition of CRC HT29 and SW620 cells' proliferation in the morin/MST-312 dose-dependent manner and a decrease in CD44+ CRC-CSC count were observed (34).

Martino-Echarri et al studied six CRC cell lines and showed that those expressing a mutated $A P C$ gene exhibited a limited response to 5-FU. The sensitivity of $A P C$-mutated $\mathrm{CRC}$ cells to 5 -FU was significantly increased by deactivating the Chk1 kinase using antisense siRNA-mediated knockdown (35). These data suggest that cancer cells (enriched by CSCs) lacking the activity of cell cycle regulating proteins are much more sensitive to proapoptotic stimulation (35).

Inhibition of epithelial-mesenchymal transition. Cancer cells derived from epithelial tissue undergo differentiation during which they lose the features of their original tissue and gain some properties of connective tissue cells, during a process called epithelial-mesenchymal transition (EMT), which is essential for acquisition of the invasion phenotype. EMT is regulated by many intracellular signaling pathways, such as Wnt, Nanog, and transforming growth factor $\beta$ (TGF $\beta$ ), whose functions are impaired during cancer transformation (36). Moreover, during EMT, non-CSCs may obtain some characteristics of CSCs through transdifferentiation, which enables the transition to the more primitive state and, as it happens, cells have been much better in acquiring therapy resistance $(37,38)$. EMT is one of the possible ways to alter the features of cancer cells, especially of CSCs, which are known to be responsible for the lack of susceptibility to standard chemotherapy (39). The most frequently diagnosed metastases in CRC patients occur in the liver, and the mean 5-year survival rate of such patients is approximately $10 \%$ (40).

\section{Crucial signaling pathways associated with efficient maintenance of CRC-CSCs: Potential targets for therapy of CRC-CSC}

Wnt signaling crucial for CRC-CSC features and survival. The $W n t / \beta$-catenin pathway has been implicated in the maintenance of the intestinal crypt stem cell pool, and Wnt signaling dysregulation (through either loss of APC function or oncogenic $\beta$-catenin mutations) has been identified in $70 \%$ CRC tumors $(41,42)$.

The Wnt pathway is evolutionary conserved and consists of a family of secreted glycoproteins, known as the 19 distinct Wnt ligands in mammals (1,42-44). The importance of this pathway is revealed by its role in the establishment of embryonic axis, cell fate determination, maintenance of adult tissue homeostasis, and regeneration $(45,46)$. Thus, loss of APC allows gastrointestinal stem and progenitor cells to continue proliferating without dying $(41,42)$. Moreover, in a proof-of-principle assay, $\beta$-catenin was demonstrated to be required for clonal growth of human CRC cell lines, and targeted deletion of the mutated, constitutively active form of $\beta$-catenin abolished the ability of the CRC cell line SW480 to grow in vitro (47). Our paper is aimed at presenting a few therapeutic compounds that target the cytoplasmic $\beta$-catenin destruction complex or inhibit expression of the target genes $(1,42)$ (Fig. 2).

A recent study has suggested that one protein, $\mathrm{p} 21$-activated kinase 1 (PAK1) is an effective stimulator of the $\mathrm{Wnt} / \beta$-catenin pathway and may be a good target for CRC treatment, since PAK1 inhibition has been found to give a synergistic effect with 5-FU (48). It has been shown that PAK1 is associated with the maintenance of stem-cell-like features of CRC-CSCs, such as the expression of CD44, tumorigenicity, and spherogenicity in both in vitro and in xenograft tumor models in vivo (48).

Pyrvinium pamoate, an antiparasitic drug, has been shown to inhibit LRP6-mediated axin degradation and the potency of $\beta$-catenin stabilization (49). Pyrvinium treatment of HCT116 and SW480 CRC lines with mutated $A P C$ or $\beta$-catenin (CTNNB1) genes inhibited both Wnt signaling and cell proliferation. Additionally, some other findings have demonstrated the allosteric activation of $\mathrm{CK} 1 \alpha$ to be an effective mechanism for inhibiting Wnt signaling (49).

The discovery of tankyrases (ADP-ribosylating enzymes) and their role in the direction of axin for ubiquitination and proteasomal degradation (50-53) has made a significant contribution to this field, as it may provide a new way of targeting the Wnt pathway (53). Inhibition of tankyrases causes the stabilization of axin, which enhances the destruction of $\beta$-catenin and reduces Wnt signaling (51). Tankyrase (Tnk) inhibition with the use of new compounds, such as JW74 and XAV939, 


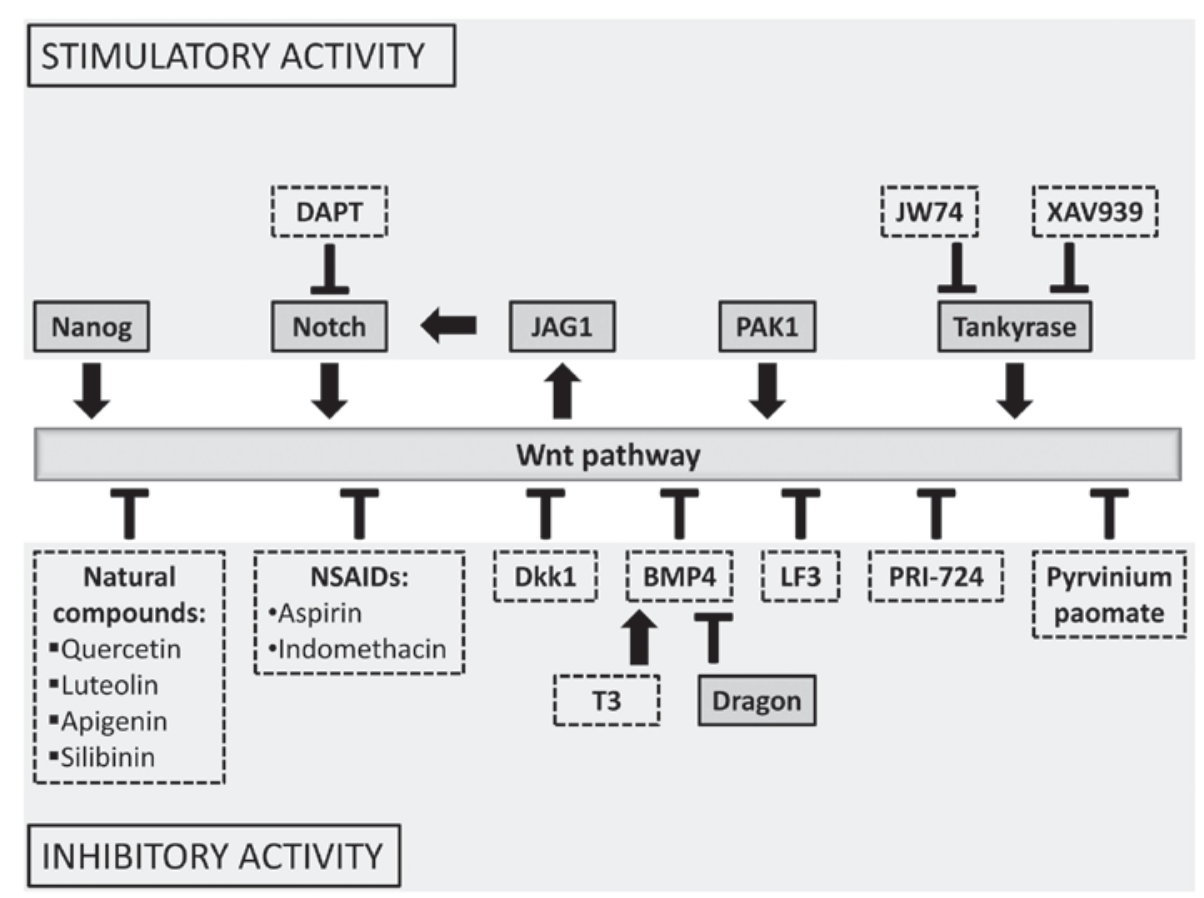

Figure 2. The influence of chosen compounds/proteins on the Wnt signaling pathway which are under consideration as either potential therapeutic targets (continuous line) or potential therapeutic/adjuvant agents (dotted line).

has also been shown to reduce growth, induce apoptosis and differentiation of cancer cells, and inhibit stem-cell properties and migration of CSC-like cells in cancer lines of diverse origins (osteosarcoma, neuroblastoma, colon) (42). Several small Tnk inhibitors have been reported to possess anticancer efficacy against cell lines of diverse origin, both in vitro and in vivo in xenograft mouse models $(50,51,54,55)$. However, the clinical utility of Tnk inhibitors is at present limited by intestinal toxicity and low therapeutic index in a mouse model (56).

PRI-724, a second generation specific CBP/catenin (cyclic AMP response element binding protein) antagonist has been shown to be safe in preclinical studies. PRI-724 disrupts the complex of $\beta$-catenin with $\mathrm{CBP}$, which reduces the expression of a subset of Wnt target genes that are important in the proliferation of CRC cells (57). Several phase I/II trials are ongoing in hematological malignancies, pancreatic cancer, and colon cancer, testing the effectiveness of PRI-724 compound (58). Moreover, PRI-724 induced differentiation of CRC xenografts, accompanied by tumor growth suppression $(42,59)$. Recently, the antineoplastic activity of the LF3 compound, which directly inhibits $\beta$-catenin/TCF4 interaction, was reported (59). LF3 treatment of colon, head, and neck cancer cells resulted in the suppression of Wnt activity and reduced self-renewal properties of CSCs (54).

Dickkopf-1 (Dkkl) as a potential target in CRC therapy. Dkk1-a potent, soluble Wnt pathway inhibitor-is reported to be a promising molecule in potential therapy of CRC (60). It has an affinity to one of the coreceptors LRP5/6 affecting the formation of the active receptor complex, Frizzl/LRP5/6, which induces endocytosis of those receptors, inhibiting Wnt signaling.

Additionally, Dkk1 has a role in embryogenesis and its level is regulated by negative feedback with Wnt pathway effectors, such as $\beta$-catenin (61). However, in CRC, this mechanism is disturbed by mutations and epigenetic changes in genes encoding $\beta$-catenin (62). It has been shown in 217 CRC patients that Dkk1 overexpression is inversely related to tumor grade, presence of metastasis, and the recurrence rate of colon cancer. In samples obtained from patients with high Dkk1 levels, increased expression of E-cadherin and cytoplasmic $\beta$-catenin, and a reduced level of vimentin (an EMT marker) were observed in comparison to Dkk1-negative samples (62). Additionally, the overexpression of Dkk1 in CRC HCT-116 cells allowed the maintenance of epithelial phenotype and led to diminished expression of transcription factors characteristic of EMT (such as Snail and Twist), but also decreased the expression of CSC markers (such as CD133 and Lgr-5) (63). An immunocytochemical analysis has shown a correlation direct between Dkk1 expression and decreased microvessel density, as well as VEGF expression in CRC tumors. CRC cells overexpressing Dkk1 formed smaller tumors following xenotransplantation, with a significantly lower number of small blood vessels (64). Hence, the Dkk1 protein can suppress the progression of the colon cancer, possibly through EMT inhibition, and could serve as a potent target of antitumor therapy $(64,65)$.

Natural compounds targeting the Wnt signaling pathway. Flavonoids, polyphenolic compounds, constitute a very large group of natural products and are one of the most characteristic classes of compounds in plant metabolism (42). Their therapeutic anticancer properties have been studied for decades and are related to the ability of these molecules to modulate the Wnt/ $\beta$-catenin signaling pathway (66-68). Flavonoids have been shown to affect different elements of this signaling pathway, varying from ligand receptor recognition and binding (Wnt/Frizzled/LRP5/6), to the methylation of genes encoding Wnt components (1). 
Quercetin, one of the most studied flavonoids in clinical trials, has been suggested as a potential anticancer drug in CRC $(1,67,68)$ due to its modulation of Wnt activity $(1,56,57)$. Quercetin interacts with $\beta$-catenin and inhibits the binding between $\beta$-catenin and TCF (69). Moreover, quercetin, as well as the flavonoids luteolin and apigenin, inhibits GSK-3 $\beta$, which is a multifunctional serine-threonine kinase involved in the formation of $\beta$-catenin destructive complex in cytoplasm $(67,68)$.

Silibinin, a flavonolignan from milk thistles, has been shown to exert chemoprevention of intestinal cancer in vitro and in vivo in a mouse model $(70,71)$. The pilot study on CRC patients who were administered silipide, an oral formulation of silibinin and phosphatidylcholine, demonstrated increased levels of silipide in blood, liver, and tumor tissue (70-72). In an experimental follow-up to that study, silibinin has been shown to suppress the growth of CRC SW480 cells in culture and the growth of xenografts through downregulation of $\beta$-catenin-dependent signaling (71). The effect of silibinin on CRC-CSCs from the HT29, SW480, and LoVo lines has been shown to be mediated by blocking IL-4/-6 protumorigenic signaling and is associated with decreased mRNA and protein levels of various CSC-associated transcription factors, signaling molecules, and surface markers (such as CD44, NANOG, TERT, SOX-2, SOX-9, and WT1). Furthermore, differentiation assays have indicated the formation of more differentiated clones by silibinin due to the shifting of CSC cell division to asymmetric. These findings support the clinical usefulness of silibinin in CRC intervention and therapy (73).

Recent clinical trials thus suggest that targeting downstream components of the neoplastic Wnt pathway may be a novel therapeutic approach for CRC treatment.

Nanog is crucial in CRC-CSC activity. Nanog is a crucial transcription factor involved in the maintenance of pluripotency and self-renewal ability in undifferentiated embryonic stem cells (74). This protein is thought to be responsible for many aspects of cancer development typical of CSCs, such as proliferation, self-renewal, migration, epithelial-mesenchymal transition, and resistance to conventional chemotherapy. Its increased expression has been found to correlate with worse prognosis in many types of cancer, including liver, kidney, colon, prostate, brain, and endometrial cancers (74-82). NANOG activation in cancer cell cultures promotes their transformation into CSCs, as has been shown following ectotopic overexpression of $N A N O G / N A N O G 8$ in the colon and prostate cancer cell lines $(75,80,81)$.

Meng et al (83) provided evidence that Nanog can be used as a prognostic factor of CRC after they examined 75 human CRC samples, which showed that overexpression of NANOG strongly correlated with poor prognosis and lymph node metastasis (83). Another study conducted immunohistochemical analysis of the expression patterns of CSC-specific markers (such as CD44, CD133, Nanog, and Oct3/4) and of immunosuppressive molecules HLA-G and HLA-E in advanced CRC tumor tissues and noncancerous colon biopsies. Statistically significant increased expression of these genes in CRC tumor tissues has been found in comparison to colon biopsies of healthy subjects. These findings suggest that CRC-CSCs may have increased expression of HLA-G and HLA-E, which may be considered as an immune-evasive mechanism and may thus become new potential targets in the elimination of CRC-CSCs (84).

Lentivirus-mediated Nanog overexpression has been revealed to significantly improve the proliferation and migratory abilities of CRC cells; Nanog was thus supposed to induce EMT through upregulation of the Slug and Snail transcription factors. Moreover, Nanog silencing mediated by interfering RNA in breast cancer MCF-7 and MDA-MB-231 cells resulted in a reduced size of the tumor in a xenotransplantation model and decreased proliferation of these cells (85). Silencing of the $N A N O G$ gene was associated with diminishing activation of cyclin D1 and cyclin-dependent kinases $(85,86)$. Downregulation of Nanog in embryonic stem P19 cells resulted in the reduction of pluripotency markers such as Fgf4, Klf2, Mtf2, Oct-4, Rex1, Sox1, Yes, and Zfp143, whereas overexpression of $N A N O G$ restored their primary expression levels (86). Interestingly, the expression of cyclin D1 and c-myc were markedly downregulated, and the cell cycle was blocked at the G0/G1 phase following the knockdown of NANOG, while the expression of cyclin E and signal transducers and activators of transcription 3 (STAT3) remained unaffected in breast cancer cells (85).

Embryonic $N A N O G$ is considered an important regulator of pluripotency, whereas NANOGP8 (NANOG-pseudogene) plays a crucial role in tumorigenesis (75). NANOGP8 can substitute for $N A N O G$ in directly promoting stemness in CRC; this conclusion was drawn from the observation that $80 \%$ of human CRC liver metastases expressed NANOG and $75 \%$ of the metastases contained NANOGP8 transcripts (76). The effects of $N A N O G$ inhibition-such as reduced spherogenicity, growth, and expression of embryonic-like transcription factors (Oct4, Sox2)-were partially reversed by the overexpression of NANOGP8 $(76,81)$. Recent studies have suggested that the knockdown of NANOG/NANOG8 genes impairs the ability to migrate and metastasize in xenograft mouse models, as well as the progression of the cell cycle and resistance to apoptosis in CRC cells and embryonic carcinoma cells $(75,76,86)$. Nanog inhibitors administered with cisplatin and other chemotherapeutics had a synergistic effect, and led to apoptosis of esophageal cancer cells (25). The lentivirus vector-mediated inhibition of NANOG/NANOG8 in CRC cells (Clone A, CX-1, LS 174T) decreased the level of Bcl-2 antiapoptotic protein and increased sensitivity to proapoptotic factors ABT-737 and ABT-199 (87). Such combined cell treatment, including inhibitors of Nanog and the modulation of proapoptotic Bcl-2 family proteins, may provide a new potential therapeutic approach for CRC-CSCs.

Immunocytochemistry and microarray examination showed that NANOG1 expression was limited only to very small population of CSCs, which made up $0.5-2 \%$ of all CRC cells (75). Furthermore, NANOG1 expression showed a positive correlation with c-JUN and Wnt/ $\beta$-catenin/TCF4 expression (75), which are known to be disrupted in CRC oncogenic transformation $(41,42)$. The ectopic expressions of OCT4 and $N A N O G$ in lung adenocarcinoma cells led to an increased percentage of $\mathrm{CD} 133^{+}$cells and sphere formation rate, and promoted drug resistance and epithelial-mesenchymal transition (EMT) $(88,89)$. Since Nanog directly inhibited EMT, it has been suggested that it should be considered as a potential therapeutic approach (89). 
TGF $\beta$ inhibitors target the epithelial-mesenchymal transition. TGF $\beta$ belongs to a superfamily of approximately 30 different pleiotropic proteins that control cell proliferation, migration, adhesion and apoptosis, maintaining tissue homeostasis. Of the three isoforms of TGF $\beta$ (TGF $\beta-1$, TGF $\beta-2$ and TGF $\beta-3)$, TGF $\beta-1$ has been most widely studied. Signaling is mediated by binding to cell membrane receptors (TGF $\beta R 1$ and TGF $\beta$ R2), which results in the phosphorylation of cytoplasmic SMAD proteins being translocated to the nucleus and binding with activators or repressors of genes associated with proliferation, survival, and migration. However, in specific situations, such as the advanced stages of cancer, TGF $\beta$ promotes the progression of the disease. During neoplastic transformation, cells lose their susceptibility to TGF $\beta$ signaling, which then acts as an autocrine promoter of invasion and metastasis $(90,91)$.

TGF $\beta$ is a positive regulator of processes associated with EMT. Among other effects, it stimulates the modification of morphology and the loss of cell polarity, decreases E-cadherin expression, and increases the expression of key transcription factors, such as Snail1/2, Twist, and Zeb1/2 (90). The synthetic proteins P17 and P144, designed to inhibit TGF $\beta 1$-mediated pathways, have recently been considered as a useful tool in a clinical approach aimed at reducing liver metastases from CRCs, lymphomas, and thymomas $(92,93)$. Additionally, the administration of peptide P17 blocked the adhesion of cancer cells to cancer fibroblasts and significantly reduced metastasis to the liver, proliferation, and angiogenesis in xenotransplantation model (94). In a CRC CT26 cell line, P17 peptide was involved in the blockage of the $\mathrm{T}$ regulatory (Treg) lymphocytes, which synergistically increased the total effect of this compound (92).

The complex analysis of the role of Kindlin- 1 in the TGF $\beta$ pathway strongly suggests that this regulatory molecule may be a new anticancer target. Kindlin-1 is known to be essential for the maintenance of the structure of cell-matrix adhesion (95). Recently, Kindling-1 has been identified as directly interacting with the key TGF $\beta / S M A D 3$ signaling components in numerous CRC cell lines (SW1116, SW480, SW620, Caco2, HCT116, RKO, LST and HT29). Kindlin-1 expression has been found to correlate with the progression of $\mathrm{CRC}$ and poor prognosis (96).

BMP regulates differentiation and maturation. Bone morphogenetic protein 4 (BMP4), belonging to the TGF $\beta$ superfamily, has been suggested to be a key regulatory factor in the differentiation of CSCs in CRC (50,97). BMP4, which is secreted by the connective tissue cells of the intestinal wall, has been shown to regulate the maturation and differentiation of normal epithelial cells via paracrine signaling $(30,98,99)$. The distribution of BMP4 increases along the colon crypt axis from bottom to top, and thus its signaling increases toward the top of the crypt. The loss of BMP4 activity in the intestinal epithelium may lead to altered maturation of epithelial cells and, in consequence, to the development of CRC (100). Recently, BMP pathway suppression has been suggested as an essential factor leading to inflammation-induced tumorigenesis of CRC in a mouse model of colonic polypoidogenesis where adenomatous polyps arise several months after induction (97). Additionally, silencing the BMP4 gene by transplacental
RNAi administration appeared to be sufficient to induce the formation of colorectal polyps in mice (101).

It has been shown that BMP4 stimulates the maturation and apoptosis of CSCs by reducing $\beta$-catenin levels in the nucleus $(98,102)$. Recombinant BMP4 was able to stimulate maturation, differentiation, and apoptosis, leading eventually to higher susceptibility to chemotherapy in human CRC-CSCs. Administration of this protein to nude mice bearing a tumor originating from CRC-CSCs improved the antitumor effect of oxaliplatin and 5-FU. The observed effects did not depend on either SMAD4 expression or microsatellite stability (103).

Additionally, a meta-analysis has demonstrated that the locus rs4444235 of the BMP4 gene may be considered as a risk factor for $\mathrm{CRC}$ in some ethnic populations (East Asians and Caucasians) (104). Moreover, Dragon (RGMb, a member of the repulsive guidance molecule family) has been found to be upregulated in CRC. Both mRNA and protein levels were increased in tumor tissue proportionally to CRC progression. The knockdown of the Dragon gene with the use of shRNA (small hairpin RNA) led to a lowered proportion of CD133+ CRC-CSCs in CT26.WT and CMT93 cell lines (105). Dragon, as a co-receptor for BMP signaling (106), has been suggested as a new target for anti-CRC therapy (105).

Recently, triiodothyronine (T3) has been described as playing a role in the regulation of BMP4 signaling by sensitizing CRC-CSCs to chemotherapeutics via significant attenuation of Wnt pathway signaling, and, by extension, via reduction of their tumorigenicity. The influence of T3 on BMP4/Wnt pathway was demonstrated when sphere-forming CSCs from patient samples treated with 5-FU and oxaliplatin presented increased cell death (up to 75\%) (107).

Blocking Notch pathway increases the efficiency of anticancer therapy. Under normal circumstances, Notch signaling clearly plays an important role in the maintenance of colon crypt homeostasis. However, the inappropriate activation of the Notch signaling pathway has been reported to be associated with CRC-CSCs. An upregulated Notch pathway has been found to play a role in CSC viability, tumorigenicity, and self-renewal $(108,109)$.

In humans, Notch signaling shows high activity in adenomas and early stage CRCs $(65,110)$, but low activity in advanced, later stage, and metastatic CRCs (111). The molecular mechanisms that cause Notch signaling to be important for early stage CRC initiation are not understood, and only a few mechanistic studies of Notch signaling in human CRC cell lines have been performed (109). Moreover, Hoey et al demonstrated that, by inhibiting DLL4 (Delta-Like 4 Ligand), an important component of the Notch pathway, with human monoclonal antibody in colon carcinoma xenografts, tumor growth and the frequency of CSCs were reduced in comparison to the control (112). Combination treatment with irinotecan and anti-hDLL4 reduced tumor growth and CRC stem cell frequency at higher levels than the anti-DLL4 treatment alone $(112,113)$. This indicates that inhibiting Notch signaling reduces CSC frequencies and sensitizes tumor cells for irinotecan treatment.

However, treatment with anti-DLL4 antibody leads to serious toxic effects in the liver, including sinusoidal dilation and centrilobular hepatocyte atrophy, as observed in mice, 
monkeys, and rats (114). Using athymic nude mice as a model system, prominent thymic atrophy in immune-competent animals treated with anti-DLL4 antibody was observed. Chronic DLL4 blockade has been shown to activate endothelial cells, disrupt the homeostasis of organs (including the heart, lung, liver, and skin) and induce vascular tumors (114). These reservations notwithstanding, further studies were conducted on both CRC patient-derived specimens (in colon tumor xenografts in NOD/SCID mice) and CRC lines (HCT116 and SW480), and these confirmed the efficacy of such potential therapeutic strategy $(115,116)$.

Van Es and colleagues (117) demonstrated that the blocking of the Notch cascade with a $\gamma$-secretase inhibitor dibenzazepine (DBZ) induced goblet cell differentiation in adenomas, even in mice carrying a mutation of the Apc gene, and subsequent tumor growth arrest (117). Additionally, another group induced expression of the Notch intracellular domain in the intestinal epithelium of transgenic mice, impairing both differentiation of the goblet and enteroendocrine cells and resulting in intensive proliferation of immature intestinal progenitor cells (118).

Notch signaling plays an important role in the determination of cell fate. In recent years, this signaling pathway has been shown to play a critical role in regulating the balance between proliferation, differentiation, and apoptosis of cells in various tissues $(108,109)$. The interaction between Notch receptors and their ligands (Jagged 1 and 2, and Delta-like 1, 3 , and 4 ) results in the proteolytic cleavage of Notch receptors by $\gamma$-secretase and other proteases, which releases the Notch intracellular domain (NICD) from the plasma membrane and initiates its subsequent translocation into the nucleus. After nuclear translocation, NICD binds to and forms a complex with one of three transcriptional regulators (119-121).

Moreover, the Jagged1 gene (JAGl), which encodes a Notch ligand, has been reported to be transcriptionally activated by the $\beta$-catenin/TCF4 complex (122). The expression of JAG1 was limited to enteroendocrine cells of the human small intestine epithelium and was undetectable in the mucosa of human large intestine. In contrast, increased expression was found in half of human colon tumors, although not all tumors with elevated Wnt signaling displayed elevated Jagged1 (122). Experiments on mice have demonstrated that elevated levels of Notch signaling in most intestinal tumors co-occurred with increased JAG1 expression. Targeting of Jagged1 could thus be effective in downregulating Notch signaling in a subset of tumors, as shown in the human HT29Cl16E CRC line (122).

Endothelial cells have been reported to promote the CSC phenotype of human CRC cells through the secretion of the soluble form of Jagged1. In human CRC specimens, CD133(a basic CRC-CSC markers) and NICD-positive CRC cells have been found to colocalize in perivascular regions $(119,123)$.

Microarray analysis has identified a group of Wnt/ $\beta$-catenin downstream genes that are directly regulated by Notch (65). These genes were repressed by $\gamma$-secretase inhibitors and upregulated by active Notch1, even in the absence of $\beta$-catenin signaling,through $\beta$-catenin-mediated transcriptional activation of the Notch-ligand Jagged1 in Ls174T CRC cells. Consistently, the expression of activated Notch1 partially reversed the effects of blocking Wnt/ $\beta$-catenin pathway in tumors implanted into nude mice. These results suggest that Notch activation, accomplished by $\beta$-catenin-mediated upregulation of Jagged1, is required for tumorigenesis in the intestine (65).

Moreover, a recent study in nude mice indicated that a subpopulation of CRC HCT116 cells chemoresistant to 5-FU and oxaliplatin, enriched in $\mathrm{CD} 133{ }^{+} \mathrm{CD} 44^{+} \mathrm{CSC}$, was more sensitive to $\gamma$-secretase inhibitor (DAPT), which depleted the cells in vitro and reduced the growth of tumors derived from these cells (124). Another study reported that upregulation of Notch1 in colonic cancer cells may provide a specific protective mechanism in response to conventional chemotherapeutics (125). These findings suggested that inhibiting the Notch pathway may be an effective strategy for targeting CRC-CSCs and overcoming the resistance of CRC cells to conventional chemotherapeutics.

\section{Metabolic target strategy}

Although it has been commonly accepted that neoplastic transformation is caused by many genetic and epigenetic factors, little is known of how it affects the metabolism of cancer cells. There are only few reports concerning selected aspects of cancer cell metabolic adaptations which impede cancer progression.

Recent studies have demonstrated overexpression of SIRT1 (silent mating type information regulation 2 homolog 1) in cancer cells resistant to 5-FU and described its implication for the promotion of tumorigenesis and the development of drug resistance (126). SIRT1 is a NAD ${ }^{+}$-dependent histone deacetylase that can deacetylate histones and a number of nonhistone proteins. SIRT1 has been shown to regulate various cellular processes, including senescence and cell survival under genotoxic and oxidative stress $(127,128)$. A recent meta-analysis showed that, in CRC patients, SIRT1 expression correlates with the development of invasion, lymph node metastasis, and TNM stage, thus suggesting that SIRT1 may be regarded as a negative prognostic marker of the overall survival rate of CRC patients (128). SIRT1 has also been shown to be one of the target genes of miR-34a, a small noncoding RNAs that may control gene expression $(126,129,130)$. It has been found that miR-34a inhibits SIRT1 expression directly through binding to the 3'-UTR of its mRNA in HCT116 CRC cells (129). The introduction of miR-34a into 5-FU-resistant DLD-1 cells significantly limited their resistance to 5-FU, which was accompanied by the reduced expression of SIRT1 and E2F family proteins $(126,129)$. These findings suggest that targeting the SIRT1 gene could decrease resistance to 5-FU in human CRC by increasing p53 apoptosis-promoting activity (129).

SIRT1 has been suggested as a key protein in maintaining stem-like features of CRC-CSCs, since SIRT1 was coexpressed with the CD133 marker, and overexpressed in colorectal CSC-like cells (131). Moreover, SIRT1 deficiency decreased percentage of $\mathrm{CD}_{133^{+}}$cells and their tumorigenicity and the abilities to form colonies and spheres (131). Additionally, the knockdown of SIRT1 gene in CRC SW620 cells reduced expression of several stemness-associated genes (such as Oct4, Nanog, and Tert) (131). These findings suggest that SIRT1 can be considered as a novel prognostic marker or a new target for anti-CRC therapy.

Other studies have focused on a different aspect of cancer cell biology-the Warburg effect, the strong tendency of cancer 
cells to switch their metabolism into anaerobic respiration (glycolysis), to secrete lactate, and take up high levels of glucose, even in the presence of oxygen in their niche; it particularly affects CSCs (132). This unusual phenomenon has been found to be associated with carcinogenesis due to the inactivation in cancer cells of some metabolic checkpoints, such as dysregulation of AMPK (energy rheostat AMP-activated protein kinase) $(10,133,134)$. The Warburg effect is postulated to create an environment favorable to CSC survival and the reprogramming of non-CSCs into CSCs (135). These observations imply that the elimination of CSCs alone may not be an effective therapeutic approach, because they can be regenerated from non-CSCs. Thus, an optimally effective cancer therapy should rely on the administration of drugs targeting different types of cells within the tumor mass.

Metformin improves anticancer therapy effectiveness. Recently, some inhibitors of AMPK have been considered as potential anticancer therapeutic agents (136-138). Metformin (MET) is the best-established compound in this group of anticancer molecules. MET is an extensively prescribed and well-tolerated first-line therapeutic drug for type-2 diabetes mellitus, which has demonstrated more effective anticancer effects in cancers characterized by hyperinsulinemia, such as breast and colon cancers $(139,140)$. This evidence supports the qualification of MET to preclinical and clinical trials of cancer therapy (136-138).

Metformin has been described as agent capable of directly and indirectly influencing cancer cells through the reduction of glucose and insulin levels in the cancer niche, which decreases cancer progression $(139,141)$. The very first observations of the effects of MET on cancer development were demonstrated in diabetes complicated with CRC; in such patients, CSCs showed lower proliferation and higher rates of apoptosis than patients not pretreated with MET (141). In the same study, it was reported that MET enhanced the antiproliferative effects of 5-FU on CD133+ CSCs in SW620, SW480, and HCT116 CRC cell lines (141-143). Recent analyses of the role of MET treatment in the occurrence of CRC among type-2 diabetes mellitus patients have shown that MET may reduce CRC incidence (144-146).

Moreover, MET has recently been identified as a potential and attractive anticancer adjuvant drug, combined with conventional chemotherapeutics to improve treatment efficacy and decrease chemotherapeutic doses. The molecular mechanisms underlying the anticancer effects of MET include insulin-dependent and AMPK-dependent effects, selective targeting of CSCs, reversion of multidrug resistance and inhibition of tumor metastasis (147-149). Positive effects of such synergistic combinatory therapy have been described for a broad spectrum of cancers, including CRC, gastric, hepatic, pancreatic, breast, lung, and prostate cancers $(139,148)$.

The combination of MET and 2-deoxyglucose induces p53-dependent apoptosis via the AMPK pathway and expression of a functional p53 in p53-deficient prostate cancer cells. In addition, such combined therapy arrests prostate cancer cells in the G2/M phase and switched the cell death pattern from autophagic to apoptotic, independently of p53 (136). In CRC SW480 cells, MET inhibited cell growth mainly by blocking the cell cycle at the G0/G1 phase, downregulating the expression of cyclin D1, and decreasing telomerase activity (143).

Another study demonstrated that MET effectively sensitizes human DLD-1, HT29, Colo205, and HCT116 cell lines to the proapoptotic activity of tumor-necrosis-factor-related apoptosis-inducing ligand (TRAIL) (134). At the same time, MET has been shown to upregulate Bax and downregulate antiapoptotic myeloid cell leukemia 1 (Mcl-1) levels in CRC cells, responsible for increased TRAIL-mediated cell death in those human CRC cell lines (134).

MET has been shown to inhibit cancer transformation and selectively kill CSCs in four genetically different types of breast cancer (MCF-7, MCF10A ER-Src, SKBR3, and MDA-MB-486). The administration of MET and doxorubicin collectively reduced the number of both $\mathrm{CD} 44^{\text {high }} \mathrm{CD} 24^{\text {low }}$ CSCs and non-CSCs during in vitro culture. Furthermore, this combinatorial therapy reduced tumor mass and prevented relapse significantly more effectively than doxorubicin alone in a xenograft mouse model (150).

Moreover, MET-treated breast cancer cell lines showed downregulation of the $\mathrm{CD} 44^{+} \mathrm{CD} 24^{-/ \text {low }}$ cell proportion via repression of EMT, including through decreasing the level of ZEB, Twist, and Snail2 transcription factors (151). Surprisingly, this combination was effective with a fourfold lower dose of doxorubicin than used in treatment with the chemotherapeutic alone, which enables the reduction of toxicity and an increase in the effectiveness of this therapeutic approach.

However, the therapeutic anticancer activity of MET seems to be controversial, as some groups have not shown its antiproliferative and proapoptotic effect in CRC lines $(141,143)$. Sui et al suggested that MET cannot induce these therapeutic effects as a single agent (152). A possible explanation of these diverse results may be the dependency of MET effectiveness on the experimental settings and cell lines used, as Sui et al (152) used HT29, HCT116, and RKO cells, while the other authors used SW620, and SW480 CRC cell lines $(141,143)$.

\section{Chemoprevention: Nonsteroid anti-inflammatory drugs in CRC therapy}

After the discovery of increased prostaglandin levels within cancer tissue, including CRC $(153,154)$, the regular use of nonsteroidal anti-inflammatory drugs (NSAIDs) was hoped to provide new therapeutic anticancer effects that would slow the progression of the disease. The issue of NSAID use in cancer prevention has been supported by growing evidence from a number of observational studies and post-trial follow-up data (153). Of all cancers, aspirin and indomethacin have been shown to be most effective at reducing the risk of CRC, and even at lower doses demonstrate a 30-40\% effectiveness in preventing CRC (153). A case-control study conducted between 1976 and 2011 and including 8634 CRC patients (and 8553 control patients) from the United States, Canada, Australia, and Germany has demonstrated that regular use of aspirin or NSAIDs reduces the risk of CRC $(153,155)$. In a genome-wide investigation of interactions between genes and environment, the use of aspirin or NSAIDs was associated with a lower risk of CRC, and this association differed depending on genetic variation at two SNPs (single-nucleotide polymorphisms) on chromosomes 12 and 15 (154). 
The common mechanism through which NSAIDs and their derivatives act is the inhibition of $\beta$-catenin/TCF transcriptional activity and, consequently, downregulation of target genes such as cyclin D1. Indomethacin is a cyclooxygenase 1 (COX-1) and COX-2 inhibitor and exhibits anti-inflammatory and analgesic properties. In addition to the more general inhibition of the $\beta$-catenin/TCF pathway mentioned above, indomethacin impairs $\beta$-catenin gene expression, as shown by the significant reduction of the corresponding mRNA in CRC cell lines (SW480, SW948, LoVo, and HCT-116) $(43,153,156,157)$. Furthermore, indomethacin stimulates $\beta$-catenin degradation in a manner independent of APC/GSK3 $\beta$ and proteasome (the Wnt 'noncanonical' pathway), even in cells bearing a mutated $A P C$ or $\beta$-catenin gene CTNNB1.

Aspirin downregulates the Wnt/ $\beta$-catenin pathway in CRC cells, leading to reduced transcription of the target genes. Unlike other NSAIDs, this effect seems to be mediated by stabilization of $\beta$-catenin in its transcriptionally inactive form (i.e., its phosphorylated form), hampering its activity as a transcription factor (155). All NSAIDs, in addition to their effects on $\beta$-catenin and related pathways, act as ligands of PPAR $\gamma$ (Peroxisome Proliferator-Activated Receptors) by stimulating PPAR $\gamma$-dependent effects, such as cell cycle block, differentiation, and apoptosis. PPAR $\gamma$ costimulates the expression of cell cycle inhibitors, such as p18, p21 and p27 (155).

Although aspirin and NSAIDs have an undisputable preventive role in CRC development, their wider use in cancer prevention needs to be carefully considered, on account of the increased risk of bleeding from the gastrointestinal tract $(153,154,156)$.

\section{Conclusions}

In this review, we have summarized the state-of-art in experimental CRC treatment targeting CSCs to prevent or reverse their chemoresistance and reduce their metastatic potential. It is hypothesized that creating combined therapy regimens, in which conventional drugs are supplemented with novel CSC-targeting drugs, might offer improved overall and cancer-free survival rates. A potential dose reduction of conventional chemotherapeutics would help limit their toxicity and improve patients' quality of life.

\section{Acknowledgements}

The study was supported by the Polish National Science Center (grant no. NN402684040).

\section{References}

1. Amado NG, Predes D, Moreno MM, Carvalho IO, Mendes FA and Abreu JG: Flavonoids and Wnt/ $\beta$-catenin signaling: Potential role in colorectal cancer therapies. Int J Mol Sci 15: 12094-12106, 2014.

2. Manhas J, Bhattacharya A, Agrawal SK, Gupta B, Das P, Deo SV, Pal S and Sen S: Characterization of cancer stem cells from different grades of human colorectal cancer. Tumour Biol 37: 14069-14081 2016.

3. Di Franco S, Todaro M, Dieli F and Stassi G: Colorectal cancer defeating? Mol Aspects Med 39: 61-81, 2014.

4. Cunningham D, Humblet Y, Siena S, Khayat D, Bleiberg H, Santoro A, Bets D, Mueser M, Harstrick A, Verslype C, et al: Cetuximab monotherapy and cetuximab plus irinotecan in irinotecan-refractory metastatic colorectal cancer. N Engl J Med 351: 337-345, 2004.
5. Van Cutsem E, Cervantes A, Nordlinger B and Arnold D; ESMO Guidelines Working Group: Metastatic colorectal cancer: ESMO clinical practice guidelines for diagnosis, treatment and follow-up. Ann Oncol 25 (Suppl 3): iii1-9, 2014.

6. Taieb J, Tabernero J, Mini E, Subtil F, Folprecht G, Van Laethem JL, Thaler J, Bridgewater J, Petersen LN, Blons H, et al: Oxaliplatin, fluorouracil, and leucovorin with or without cetuximab in patients with resected stage III colon cancer (PETACC-8): An open-label, randomised phase 3 trial. Lancet Oncol 15: 862-873, 2014.

7. Binefa G, Rodríguez-Moranta F, Teule A and Medina-Hayas M: Colorectal cancer: From prevention to personalized medicine. World J Gastroenterol 20: 6786-6808, 2014.

8. Sauer R, Liersch T, Merkel S, Fietkau R, Hohenberger W, Hess C, Becker H, Raab HR, Villanueva MT, Witzigmann H, et al: Preoperative versus postoperative chemoradiotherapy for locally advanced rectal cancer: Results of the German CAO/ARO/AIO-94 randomized phase III trial after a median follow-up of 11 years. J Clin Oncol 30: 1926-1933, 2012.

9. Khan K, Wale A, Brown G and Chau I: Colorectal cancer with liver metastases: Neoadjuvant chemotherapy, surgical resection first or palliation alone? World J Gastroenterol 20: 12391-12406, 2014.

10. Paldino E, Tesori V, Casalbore P, Gasbarrini A and Puglisi MA: Tumor initiating cells and chemoresistance: Which is the best strategy to target colon cancer stem cells? Biomed Res Int 2014: $859871,2014$.

11. O'Brien CA, Pollett A, Gallinger S and Dick JE: A human colon cancer cell capable of initiating tumour growth in immunodeficient mice. Nature 445: 106-110, 2007.

12. Puglisi MA, Barba M, Corbi M, Errico MF, Giorda E, Saulnier N, Boninsegna A, Piscaglia AC, Carsetti R, Cittadini A, et al: Identification of Endothelin-1 and NR4A2 as CD133-regulated genes in colon cancer cells. J Pathol 225: 305-314, 2011.

13. Ricci-Vitiani L, Lombardi DG, Pilozzi E, Biffoni M, Todaro M, Peschle $\mathrm{C}$ and De Maria R: Identification and expansion of human colon-cancer-initiating cells. Nature 445: 111-115, 2007.

14. Shmelkov SV, Butler JM, Hooper AT, Hormigo A, Kushner J, Milde T, St Clair R, Baljevic M, White I, Jin DK, et al: CD133 expression is not restricted to stem cells, and both CD133+ and CD133- metastatic colon cancer cells initiate tumors. J Clin Invest 118: 2111-2120, 2008.

15. Todaro M, Perez Alea M, Scopelliti A, Medema JP and Stassi G: IL-4-mediated drug resistance in colon cancer stem cells. Cell Cycle 7: 309-313, 2008.

16. Huang EH, Hynes MJ, Zhang T, Ginestier C, Dontu G, Appelman H, Fields JZ, Wicha MS and Boman BM: Aldehyde dehydrogenase 1 is a marker for normal and malignant human colonic stem cells (SC) and tracks SC overpopulation during colon tumorigenesis. Cancer Res 69: 3382-3389, 2009.

17. Lin SP, Lee YT, Yang SH, Miller SA, Chiou SH, Hung MC and Hung SC: Colon cancer stem cells resist antiangiogenesis therapy-induced apoptosis. Cancer Lett 328: 226-234, 2013.

18. Zhang $\mathrm{Z}$ and Huang J: Intestinal stem cells-types and markers. Cell Biol Int 37: 406-414, 2013.

19. Dallas NA, Xia L, Fan F, Gray MJ, Gaur P, van Buren G II, Samuel S, Kim MP, Lim SJ and Ellis LM: Chemoresistant colorectal cancer cells, the cancer stem cell phenotype, and increased sensitivity to insulin-like growth factor-I receptor inhibition. Cancer Res 69: 1951-1957, 2009.

20. Huang EH and Wicha MS: Colon cancer stem cells: Implications for prevention and therapy. Trends Mol Med 14: 503-509, 2008.

21. Yu ZQ, Zhang C, Wang H, Lao XY, Chai R, Gao XH, Cao GW and Fu CG: Downregulation of ATP-binding cassette subfamily $\mathrm{C}$ member 4 increases sensitivity to neoadjuvant radiotherapy for locally advanced rectal carcinoma. Dis Colon Rectum 56: 600-608, 2013.

22. Kozovska Z, Gabrisova V and Kucerova L: Colon cancer: Cancer stem cells markers, drug resistance and treatment. Biomed Pharmacother 68: 911-916, 2014.

23. Vermeulen L, Todaro M, de Sousa Mello F, Sprick MR, Kemper K, Perez Alea M, Richel DJ, Stassi G and Medema JP: Single-cell cloning of colon cancer stem cells reveals a multi-lineage differentiation capacity. Proc Natl Acad Sci USA 105: 13427-13432, 2008.

24. Ong CW, Kim LG, Kong HH, Low LY, Iacopetta B, Soong R and Salto-Tellez M: CD133 expression predicts for non-response to chemotherapy in colorectal cancer. Mod Pathol 23: 450-457, 2010.

25. Du Y, Shi L, Wang T, Liu Z and Wang Z: Nanog siRNA plus cisplatin may enhance the sensitivity of chemotherapy in esophageal cancer. J Cancer Res Clin Oncol 138: 1759-1767, 2012. 
26. Du L, Wang H, He L, Zhang J, Ni B, Wang X, Jin H, Cahuzac N, Mehrpour M, Lu Y and Chen Q: CD44 is of functional importance for colorectal cancer stem cells. Clin Cancer Res 14: 6751-6760, 2008.

27. Berretta M, Alessandrini L, De Divitiis C, Nasti G, Lleshi A, Di Francia R, Facchini G, Cavaliere C, Buonerba C and Canzonieri V: Serum and tissue markers in colorectal cancer: State of art. Crit Rev Oncol Hematol 111: 103-116, 2017.

28. Honoki K, Fujii H, Kubo A, Kido A, Mori T, Tanaka Y and Tsujiuchi T: Possible involvement of stem-like populations with elevated ALDH1 in sarcomas for chemotherapeutic drug resistance. Oncol Rep 24: 501-505, 2010.

29. Kim MP, Fleming JB, Wang H, Abbruzzese JL, Choi W, Kopetz S, McConkey DJ, Evans DB and Gallick GE: ALDH activity selectively defines an enhanced tumor-initiating cell population relative to $\mathrm{CD} 133$ expression in human pancreatic adenocarcinoma. PLoS One 6: e20636, 2011.

30. Koppaka V, Thompson DC, Chen Y, Ellermann M, Nicolaou KC, Juvonen RO, Petersen D, Deitrich RA, Hurley TD and Vasiliou V: Aldehyde dehydrogenase inhibitors: A comprehensive review of the pharmacology, mechanism of action, substrate specificity, and clinical application. Pharmacol Rev 64: 520-539, 2012.

31. Su Y, Qiu Q, Zhang X, Jiang Z, Leng Q, Liu Z, Stass SA and Jiang F: Aldehyde dehydrogenase 1 A1-positive cell population is enriched in tumor-initiating cells and associated with progression of bladder cancer. Cancer Epidemiol Biomarkers Prev 19: 327-337, 2010.

32. Croker AK and Allan AL: Inhibition of aldehyde dehydrogenase (ALDH) activity reduces chemotherapy and radiation resistance of stem-like ALDHhiCD $44^{+}$human breast cancer cells. Breast Cancer Res Treat 133: 75-87, 2012.

33. Nowak D, Stewart D and Koeffler HP: Differentiation therapy of leukemia: 3 decades of development. Blood 113: 3655-3665, 2009.

34. Chung SS, Oliva B, Dwabe S and Vadgama JV: Combination treatment with flavonoid morin and telomerase inhibitor MST-312 reduces cancer stem cell traits by targeting STAT3 and telomerase. Int J Oncol 49: 487-498, 2016.

35. Martino-Echarri E, Henderson BR and Brocardo MG: Targeting the DNA replication checkpoint by pharmacologic inhibition of Chk1 kinase: A strategy to sensitize APC mutant colon cancer cells to 5-fluorouracil chemotherapy. Oncotarget 5: 9889-9900, 2014.

36. Thiery JP, Acloque H, Huang RY and Nieto MA: Epithelial-mesenchymal transitions in development and disease. Cell 139: 871-890, 2009.

37. Pulito C, Donzelli S, Muti P, Puzzo L, Strano S and Blandino G: microRNAs and cancer metabolism reprogramming: The paradigm of metformin. Ann Transl Med 2: 58, 2014.

38. Mani SA, Guo W, Liao MJ, Eaton EN, Ayyanan A, Zhou AY, Brooks M, Reinhard F, Zhang CC, Shipitsin M, et al: The epithelial-mesenchymal transition generates cells with properties of stem cells. Cell 133: 704-715, 2008

39. Singh A and Settleman J: EMT, cancer stem cells and drug resistance: An emerging axis of evil in the war on cancer. Oncogene 29: 4741-4751, 2010.

40. Zubeldia IG, Bleau AM, Redrado M, Serrano D, Agliano A, Gil-Puig C, Vidal-Vanaclocha F, Lecanda J and Calvo A: Epithelial to mesenchymal transition and cancer stem cell phenotypes leading to liver metastasis are abrogated by the novel TGF 31 -targeting peptides P17 and P144. Exp Cell Res 319: $12-22,2013$

41. Brenner H, Kloor M and Pox CP: Colorectal cancer. Lancet 383: 1490-1502, 2014

42. de Sousa E Melo F and Vermeulen L: Wnt signaling in cancer stem cell biology. Cancers (Basel) 8: pii: E60, 2016.

43. Anastas JN and Moon RT: WNT signalling pathways as therapeutic targets in cancer. Nat Rev Cancer 13: 11-26, 2013.

44. Wierzbicki PM and Rybarczyk A: The Hippo pathway in colorectal cancer. Folia Histochem Cytobiol 53: 105-119, 2015.

45. Tian H, Biehs B, Warming S, Leong KG, Rangell L, Klein OD and de Sauvage FJ: A reserve stem cell population in small intestine renders Lgr5-positive cells dispensable. Nature 478: 255-259, 2011

46. Yan KS, Chia LA, Li X, Ootani A, Su J, Lee JY, Su N, Luo Y, Heilshorn SC, Amieva MR, et al: The intestinal stem cell markers Bmil and Lgr5 identify two functionally distinct populations. Proc Natl Acad Sci USA 109: 466-471, 2012.

47. Kim JS, Crooks H, Foxworth A and Waldman T: Proof-of-principle: Oncogenic beta-catenin is a valid molecular target for the development of pharmacological inhibitors. Mol Cancer Ther 1: 1355-1359, 2002 .
48. Huynh N, Shulkes A, Baldwin G and He H: Up-regulation of stem cell markers by P21-activated kinase 1 contributes to 5-fluorouracil resistance of colorectal cancer. Cancer Biol Ther 17: 813-823, 2016

49. Thorne CA, Hanson AJ, Schneider J, Tahinci E, Orton D, Cselenyi CS, Jernigan KK, Meyers KC, Hang BI, Waterson AG, et al: Small-molecule inhibition of Wnt signaling through activation of casein kinase $1 \alpha$. Nat Chem Biol 6: 829-836, 2010

50. Chen B, Dodge ME, Tang W, Lu J, Ma Z, Fan CW, Wei S, Hao W, Kilgore J, Williams NS, et al: Small molecule-mediated disruption of Wnt-dependent signaling in tissue regeneration and cancer. Nat Chem Biol 5: 100-107, 2009.

51. Huang SM, Mishina YM, Liu S, Cheung A, Stegmeier F, Michaud GA, Charlat O, Wiellette E, Zhang Y, Wiessner S, et al: Tankyrase inhibition stabilizes axin and antagonizes Wnt signalling. Nature 461: 614-620, 2009.

52. Riffell JL, Lord CJ and Ashworth A: Tankyrase-targeted therapeutics: Expanding opportunities in the PARP family. Nat Rev Drug Discov 11: 923-936, 2012.

53. Polakis P: Drugging Wnt signalling in cancer. EMBO J 31: 2737-2746, 2012.

54. Waaler J, Machon O, Tumova L, Dinh H, Korinek V, Wilson SR, Paulsen JE, Pedersen NM, Eide TJ, Machonova O, et al: A novel tankyrase inhibitor decreases canonical Wnt signaling in colon carcinoma cells and reduces tumor growth in conditional APC mutant mice. Cancer Res 72: 2822-2832, 2012.

55. Lau T, Chan E, Callow M, Waaler J, Boggs J, Blake RA, Magnuson S, Sambrone A, Schutten M, Firestein R, et al: A novel tankyrase small-molecule inhibitor suppresses APC mutation-driven colorectal tumor growth. Cancer Res 73: 3132-3144, 2013.

56. Zhong Y, Katavolos P, Nguyen T, Lau T, Boggs J, Sambrone A Kan D, Merchant M, Harstad E, Diaz D, et al: Tankyrase inhibition causes reversible intestinal toxicity in mice with a therapeutic index <1. Toxicol Pathol 44: 267-278, 2016.

57. Lenz HJ and Kahn M: Safely targeting cancer stem cells via selective catenin coactivator antagonism. Cancer Sci 105: 1087-1092, 2014

58. Duchartre Y, Kim YM and Kahn M: The Wnt signaling pathway in cancer. Crit Rev Oncol Hematol 99: 141-149, 2016.

59. Fang L, Zhu Q, Neuenschwander M, Specker E, Wulf-Goldenberg A, Weis WI, von Kries JP and Birchmeier W: A small-molecule antagonist of the $\beta$-catenin/TCF4 interaction blocks the self-renewal of cancer stem cells and suppresses tumorigenesis. Cancer Res 76: 891-901, 2016.

60. Aguilera Ó, González-Sancho JM, Zazo S, Rincón R, Fernández AF, Tapia O, Canals F, Morte B, Calvanese V, Orgaz JL, et al: Nuclear DICKKOPF-1 as a biomarker of chemoresistance and poor clinical outcome in colorectal cancer. Oncotarget 6: 5903-5917, 2015.

61. González-Sancho JM, Aguilera O, García JM, Pendás-Franco N, Peña C, Cal S, García de Herreros A, Bonilla F and Muñoz A: The Wnt antagonist DICKKOPF-1 gene is a downstream target of beta-catenin/TCF and is downregulated in human colon cancer. Oncogene 24: 1098-1103, 2005.

62. Qi L, Sun B, Liu Z, Li H, Gao J and Leng X: Dickkopf-1 inhibits epithelial-mesenchymal transition of colon cancer cells and contributes to colon cancer suppression. Cancer Sci 103: 828-835, 2012.

63. Peinado H, Olmeda D and Cano A: Snail, Zeb and bHLH factors in tumour progression: An alliance against the epithelial phenotype? Nat Rev Cancer 7: 415-428, 2007.

64. Liu Z, Sun B, Qi L, Li Y, Zhao X, Zhang D and Zhang Y: Dickkopf-1 expression is down-regulated during the colorectal adenoma-carcinoma sequence and correlates with reduced microvessel density and VEGF expression. Histopathology 67: $158-166,2015$

65. Rodilla V, Villanueva A, Obrador-Hevia A, Robert-Moreno A, Fernández-Majada V, Grilli A, López-Bigas N, Bellora N, Albà MM, Torres F, et al: Jagged 1 is the pathological link between Wnt and Notch pathways in colorectal cancer. Proc Natl Acad Sci USA 106: 6315-6320, 2009.

66. Atashpour S, Fouladdel S, Movahhed TK, Barzegar E, Ghahremani MH, Ostad SN and Azizi E: Quercetin induces cell cycle arrest and apoptosis in CD133(+) cancer stem cells of human colorectal HT29 cancer cell line and enhances anticancer effects of doxorubicin. Iran J Basic Med Sci 18: 635-643, 2015.

67. Temraz S, Mukherji D and Shamseddine A: Potential targets for colorectal cancer prevention. Int J Mol Sci 14: 17279-17303, 2013. 
68. Johnson JL, Rupasinghe SG, Stefani F, Schuler MA and Gonzalez de Mejia E: Citrus flavonoids luteolin, apigenin, and quercetin inhibit glycogen synthase kinase- $3 \beta$ enzymatic activity by lowering the interaction energy within the binding cavity. J Med Food 14: 325-333, 2011.

69. Ning Y, Zhang W, Hanna DL, Yang D, Okazaki S, Berger MD, Miyamoto Y, Suenaga M, Schirripa M, El-Khoueiry A and Lenz HJ: Clinical relevance of EMT and stem-like gene expression in circulating tumor cells of metastatic colorectal cancer patients. Pharmacogenomics J: Aug 9, 2016 (Epub ahead of print).

70. Rajamanickam S, Velmurugan B, Kaur M, Singh RP and Agarwal R: Chemoprevention of intestinal tumorigenesis in APCmin/+ mice by silibinin. Cancer Res 70: 2368-2378, 2010.

71. Kaur M, Velmurugan B, Tyagi A, Agarwal C, Singh RP and Agarwal R: Silibinin suppresses growth of human colorectal carcinoma SW480 cells in culture and xenograft through down-regulation of beta-catenin-dependent signaling. Neoplasia 12: 415-424, 2010.

72. Hoh C, Boocock D, Marczylo T, Singh R, Berry DP, Dennison AR, Hemingway D, Miller A, West K, Euden S, et al: Pilot study of oral silibinin, a putative chemopreventive agent, in colorectal cancer patients: Silibinin levels in plasma, colorectum, and liver and their pharmacodynamic consequences. Clin Cancer Res 12: 2944-2950, 2006.

73. Kumar S, Raina K, Agarwal C and Agarwal R: Silibinin strongly inhibits the growth kinetics of colon cancer stem cell-enriched spheroids by modulating interleukin 4/6-mediated survival signals. Oncotarget 5: 4972-4989, 2014.

74. Wang ML, Chiou SH and Wu CW: Targeting cancer stem cells: Emerging role of Nanog transcription factor. Onco Targets Ther 6: 1207-1220, 2013

75. Ibrahim EE, Babaei-Jadidi R, Saadeddin A, Spencer-Dene B, Hossaini S, Abuzinadah M, Li N, Fadhil W, Ilyas M, Bonnet D and Nateri AS: Embryonic NANOG activity defines colorectal cancer stem cells and modulates through AP1- and TCF-dependent mechanisms. Stem Cells 30: 2076-2087, 2012.

76. Zhang J, Espinoza LA, Kinders RJ, Lawrence SM, Pfister TD Zhou M, Veenstra TD, Thorgeirsson SS and Jessup JM: NANOG modulates stemness in human colorectal cancer. Oncogene 32 4397-4405, 2013.

77. Lee TK, Castilho A, Cheung VC, Tang KH, Ma S and Ng IO $\mathrm{CD} 24(+)$ liver tumor-initiating cells drive self-renewal and tumor initiation through STAT3-mediated NANOG regulation. Cell Stem Cell 9: 50-63, 2011.

78. Niu CS, Li DX, Liu YH, Fu XM, Tang SF and Li J: Expression of NANOG in human gliomas and its relationship with undifferentiated glioma cells. Oncol Rep 26: 593-601, 2011

79. Zhou X, Zhou YP, Huang GR, Gong BL, Yang B, Zhang DX, $\mathrm{Hu} \mathrm{P}$ and $\mathrm{Xu} \mathrm{SR}$ : Expression of the stem cell marker, Nanog, in human endometrial adenocarcinoma. Int J Gynecol Pathol 30: 262-270, 2011.

80. Bussolati B, Bruno S, Grange C, Ferrando U and Camussi G: Identification of a tumor-initiating stem cell population in human renal carcinomas. FASEB J 22: 3696-3705, 2008.

81. Jeter CR, Liu B, Liu X, Chen X, Liu C, Calhoun-Davis T, Repass J, Zaehres H, Shen JJ and Tang DG: NANOG promotes cancer stem cell characteristics and prostate cancer resistance to androgen deprivation. Oncogene 30: 3833-3845, 2011.

82. Zbinden M, Duquet A, Lorente-Trigos A, Ngwabyt SN, Borges I and Ruiz i Altaba A: NANOG regulates glioma stem cells and is essential in vivo acting in a cross-functional network with GLI1 and p53. EMBO J 29: 2659-2674, 2010.

83. Meng HM, Zheng P, Wang XY, Liu C, Sui HM, Wu SJ, Zhou J, Ding YQ and Li J: Over-expression of Nanog predicts tumor progression and poor prognosis in colorectal cancer. Cancer Biol Ther 9: 295-302, 2010.

84. Özgül Özdemir RB, Özdemir AT, Oltulu F, Kurt K, Yiğittürk G and Kirmaz C: A comparison of cancer stem cell markers and nonclassical major histocompatibility complex antigens in colorectal tumor and noncancerous tissues. Ann Diagn Pathol 25: 60-63, 2016.

85. Han J, Zhang F, Yu M, Zhao P, Ji W, Zhang H, Wu B, Wang Y and Niu R: RNA interference-mediated silencing of NANOG reduces cell proliferation and induces G0/G1 cell cycle arrest in breast cancer cells. Cancer Lett 321: 80-88, 2012.

86. Choi SC, Choi JH, Park CY, Ahn CM, Hong SJ and Lim DS: Nanog regulates molecules involved in stemness and cell cycle-signaling pathway for maintenance of pluripotency of P19 embryonal carcinoma stem cells. J Cell Physiol 227: 3678-3692, 2012.
87. Mattoo AR, Zhang J, Espinoza LA and Jessup JM: Inhibition of NANOG/NANOGP8 downregulates MCL-1 in colorectal cancer cells and enhances the therapeutic efficacy of BH3 mimetics. Clin Cancer Res 20: 5446-5455, 2014

88. Chiou SH, Wang ML, Chou YT, Chen CJ, Hong CF Hsieh WJ, Chang HT, Chen YS, Lin TW, Hsu HS and Wu CW: Coexpression of Oct 4 and Nanog enhances malignancy in lung adenocarcinoma by inducing cancer stem cell-like properties and epithelial-mesenchymal transdifferentiation. Cancer Res 70: 10433-10444, 2010.

89. Pan Q, Meng L, Ye J, Wei X, Shang Y, Tian Y, He Y, Peng Z, Chen L, Chen W, et al: Transcriptional repression of miR-200 family members by Nanog in colon cancer cells induces epithelial-mesenchymal transition (EMT). Cancer Lett 392: 26-38, 2017.

90. Abetov D, Mustapova Z, Saliev T and Bulanin D: Biomarkers and signaling pathways of colorectal cancer stem cells. Tumour Biol 36: 1339-1353, 2015.

91. Yokobori T and Nishiyama M: TGF- $\beta$ signaling in gastrointestinal cancers: Progress in basic and clinical research. J Clin Med 6: pii: E11, 2017.

92.Gil-Guerrero L, Dotor J, Huibregtse IL, Casares N, López-Vázquez AB, Rudilla F, Riezu-Boj JI, López-Sagaseta J, Hermida J, Van Deventer S, et al: In vitro and in vivo down-regulation of regulatory $T$ cell activity with a peptide inhibitor of TGF-beta1. J Immunol 181: 126-135, 2008.

93. Llopiz D, Dotor J, Casares N, Bezunartea J, Díaz-Valdés N, Ruiz M, Aranda F, Berraondo P, Prieto J, Lasarte JJ, et al: Peptide inhibitors of transforming growth factor-beta enhance the efficacy of antitumor immunotherapy. Int J Cancer 125: 2614-2623, 2009.

94. Gonzalez-Zubeldia I, Dotor J, Redrado M, Bleau AM, Manrique I, de Aberasturi AL, Villalba $M$ and Calvo A: Co-migration of colon cancer cells and CAFs induced by TGF $\beta_{1}$ enhances liver metastasis. Cell Tissue Res 359: 829-839, 2015

95. Zhan J, Yang M, Zhang J, Guo Y, Liu W and Zhang H: Kindler syndrome protein Kindlin-1 is mainly expressed in adult tissues originating from ectoderm/endoderm. Sci China Life Sci 58: 432-441, 2015

96. Kong J, Du J, Wang Y, Yang M, Gao J, Wei X, Fang W, Zhan J and Zhang H: Focal adhesion molecule Kindlin-1 mediates activation of TGF- $\beta$ signaling by interacting with TGF- $\beta$ RI, SARA and Smad3 in colorectal cancer cells. Oncotarget 7: 76224-76237, 2016

97. Karagiannis GS, Afaloniati H, Karamanavi E, Poutahidis T and Angelopoulou K: BMP pathway suppression is an early event in inflammation-driven colon neoplasmatogenesis of uPA-deficient mice. Tumour Biol 37: 2243-2255, 2016.

98. Kim JS, Crooks H, Dracheva T, Nishanian TG, Singh B, Jen J and Waldman T: Oncogenic beta-catenin is required for bone morphogenetic protein 4 expression in human cancer cells. Cancer Res 62: 2744-2748, 2002.

99. Lubbe SJ, Pittman AM, Matijssen C, Twiss P, Olver B, Lloyd A, Qureshi M, Brown N, Nye E, Stamp G, et al: Evaluation of germline BMP4 mutation as a cause of colorectal cancer. Hum Mutat 32: E1928-E1938, 2011.

100. Kosinski C, Li VS, Chan AS, Zhang J, Ho C, Tsui WY, Chan TL, Mifflin RC, Powell DW, Yuen ST, et al: Gene expression patterns of human colon tops and basal crypts and BMP antagonists as intestinal stem cell niche factors. Proc Natl Acad Sci USA 104 15418-15423, 2007

101. Jin X, Chen Z, Xiang L, Luo Q, Guo Z, Ding X and Jin X: Colorectal polyp model established by transplacental BMP4 RNAi. Mol Med Rep 10: 33-38, 2014.

102. Dou $\mathrm{J}$ and $\mathrm{Gu} \mathrm{N}$ : Emerging strategies for the identification and targeting of cancer stem cells. Tumour Biol 31: 243-253, 2010.

103. Lombardo Y, Scopelliti A, Cammareri P, Todaro M, Iovino F, Ricci-Vitiani L, Gulotta G, Dieli F, de Maria R and Stassi G: Bone morphogenetic protein 4 induces differentiation of colorectal cancer stem cells and increases their response to chemotherapy in mice. Gastroenterology 140: 297-309, 2011.

104. Zhou L, Xie J, Gu EL, Huang Y, Qu Y, Xu AP, Zhu Y and Wang $\mathrm{H}$ : Common genetic variant on BMP4 contributes to colorectal adenoma and cancer: A meta-analysis based on 15 studies. Cytokine 72: 154-159, 2015.

105. Shi Y, Chen GB, Huang XX, Xiao CX, Wang HH, Li YS, Zhang JF, Li S, Xia Y, Ren JL and Guleng B: Dragon (repulsive guidance molecule $b, \mathrm{RGMb}$ ) is a novel gene that promotes colorectal cancer growth. Oncotarget 6: 20540-20554, 2015. 
106. Halbrooks PJ, Ding R, Wozney JM and Bain G: Role of RGM coreceptors in bone morphogenetic protein signaling. J Mol Signal 2: 4, 2007.

107. Catalano V, Dentice M, Ambrosio R, Luongo C, Carollo R, Benfante A, Todaro M, Stassi G and Salvatore D: Activated thyroid hormone promotes differentiation and chemotherapeutic sensitization of colorectal cancer stem cells by regulating Wnt and BMP4 signaling. Cancer Res 76: 1237-1244, 2016.

108. Miyamoto S and Rosenberg DW: Role of Notch signaling in colon homeostasis and carcinogenesis. Cancer Sci 102: 1938-1942, 2011.

109. Sikandar SS, Pate KT, Anderson S, Dizon D, Edwards RA, Waterman ML and Lipkin SM: NOTCH signaling is required for formation and self-renewal of tumor-initiating cells and for repression of secretory cell differentiation in colon cancer. Cancer Res 70: 1469-1478, 2010.

110. Reedijk M, Odorcic S, Zhang H, Chetty R, Tennert C, Dickson BC, Lockwood G, Gallinger S and Egan SE: Activation of Notch signaling in human colon adenocarcinoma. Int J Oncol 33: 1223-1229, 2008.

111. Fre S, Pallavi SK, Huyghe M, Laé M, Janssen KP, Robine S, Artavanis-Tsakonas S and Louvard D: Notch and Wnt signals cooperatively control cell proliferation and tumorigenesis in the intestine. Proc Natl Acad Sci USA 106: 6309-6314, 2009.

112. Hoey T, Yen WC, Axelrod F, Basi J, Donigian L, Dylla S, Fitch-Bruhns M, Lazetic S, Park IK, Sato A, et al: DLL4 blockade inhibits tumor growth and reduces tumor-initiating cell frequency. Cell Stem Cell 5: 168-177, 2009.

113. Liu Z, Fan F, Wang A, Zheng S and Lu Y: Dll4-Notch signaling in regulation of tumor angiogenesis. J Cancer Res Clin Oncol 140 525-536, 2014.

114. Yan M, Callahan CA, Beyer JC, Allamneni KP, Zhang G, Ridgway JB, Niessen K and Plowman GD: Chronic DLL4 blockade induces vascular neoplasms. Nature 463: E6-E7, 2010.

115. Fischer M, Yen WC, Kapoun AM, Wang M, O'Young G, Lewicki J, Gurney A and Hoey T: Anti-DLL4 inhibits growth and reduces tumor-initiating cell frequency in colorectal tumors with oncogenic KRAS mutations. Cancer Res 71: 1520-1525, 2011.

116. He P, Liang J, Shao T, Guo Y, Hou Y and Li Y: HDAC5 promotes colorectal cancer cell proliferation by up-regulating DLL4 expression. Int J Clin Exp Med 8: 6510-6516, 2015.

117. van Es JH, Sato T, van de Wetering M, Lyubimova A, Gregorieff A, Zeinstra L, van den Born M, Korving J, Martens ACM, van den Oudenaarden A and Clevers H: Dll1+ secretory progenitor cells revert to stem cells upon crypt damage. Nat Cell Biol 14: 1099-1104, 2012.

118. Fre S, Huyghe M, Mourikis P, Robine S, Louvard D and Artavanis-Tsakonas S: Notch signals control the fate of immature progenitor cells in the intestine. Nature 435: 964-968, 2005.

119. Grochowski CM, Loomes KM and Spinner NB: Jagged1 (JAG1): Structure, expression, and disease associations. Gene 576: 381-384, 2016

120. Bray SJ: Notch signalling: A simple pathway becomes complex. Nat Rev Mol Cell Biol 7: 678-689, 2006.

121. van Es JH, van Gijn ME, Riccio O, van den Born M, Vooijs M, Begthel H, Cozijnsen M, Robine S, Winton DJ, Radtke F and Clevers H: Notch/gamma-secretase inhibition turns proliferative cells in intestinal crypts and adenomas into goblet cells. Nature 435: 959-963, 2005.

122. Guilmeau S, Flandez M, Mariadason JM and Augenlicht LH: Heterogeneity of Jagged1 expression in human and mouse intestinal tumors: Implications for targeting Notch signaling. Oncogene 29: 992-1002, 2010.

123. Lu J, Ye X, Fan F, Xia L, Bhattacharya R, Bellister S, Tozzi F, Sceusi E, Zhou Y, Tachibana I, et al: Endothelial cells promote the colorectal cancer stem cell phenotype through a soluble form of Jagged-1. Cancer Cell 23: 171-185, 2013.

124. Huang R, Wang G, Song Y, Tang Q, You Q, Liu Z, Chen Y, Zhang Q, Li J, Muhammand S and Wang X: Colorectal cancer stem cell and chemoresistant colorectal cancer cell phenotypes and increased sensitivity to Notch pathway inhibitor. Mol Med Rep 12: 2417-2424, 2015.

125. Meng RD, Shelton CC, Li YM, Qin LX, Notterman D, Paty PB and Schwartz GK: Gamma-secretase inhibitors abrogate oxaliplatin-induced activation of the Notch-1 signaling pathway in colon cancer cells resulting in enhanced chemosensitivity. Cancer Res 69: 573-582, 2009.
126. Akao Y, Noguchi S, Iio A, Kojima K, Takagi T and Naoe T: Dysregulation of microRNA-34a expression causes drug-resistance to 5-FU in human colon cancer DLD-1 cells. Cancer Lett 300: 197-204, 2011.

127. Horio Y, Hayashi T, Kuno A and Kunimoto R: Cellular and molecular effects of sirtuins in health and disease. Clin Sci (Lond) 121: 191-203, 2011.

128. Zu G, Ji A, Zhou T and Che N: Clinicopathological significance of SIRT1 expression in colorectal cancer: A systematic review and meta analysis. Int J Surg 26: 32-37, 2016.

129. Yamakuchi M, Ferlito M and Lowenstein CJ: miR-34a repression of SIRT1 regulates apoptosis. Proc Natl Acad Sci USA 105: 13421-13426, 2008.

130. Stiegelbauer V, Perakis S, Deutsch A, Ling H, Gerger A and Pichler M: MicroRNAs as novel predictive biomarkers and therapeutic targets in colorectal cancer. World J Gastroenterol 20: 11727-11735, 2014.

131. Chen X, Sun K, Jiao S, Cai N, Zhao X, Zou H, Xie Y, Wang Z, Zhong M and Wei L: High levels of SIRT1 expression enhance tumorigenesis and associate with a poor prognosis of colorectal carcinoma patients. Sci Rep 4: 7481, 2014.

132. Gentric G, Mieulet V and Mechta-Grigoriou F: Heterogeneity in cancer metabolism: New concepts in an old field. Antioxid Redox Signal 26: 462-485, 2017.

133. Stubbs M and Griffiths JR: The altered metabolism of tumors: HIF-1 and its role in the Warburg effect. Adv Enzyme Regul 50: 44-55, 2010.

134. Park SH, Lee DH, Kim JL, Kim BR, Na YJ, Jo MJ, Jeong YA, Lee SY, Lee SI, Lee YY and Oh SC: Metformin enhances TRAIL-induced apoptosis by Mcl-1 degradation via Mule in colorectal cancer cells. Oncotarget 7: 59503-59518, 2016.

135. Menendez JA, Joven J, Cufi S, Corominas-Faja B, Oliveras-Ferraros C, Cuyàs $\mathrm{E}$, Martin-Castillo $\mathrm{B}$, López-Bonet E, Alarcón T and Vazquez-Martin A: The Warburg effect version 2.0: Metabolic reprogramming of cancer stem cells. Cell Cycle 12: 1166-1179, 2013.

136. Ben Sahra I, Laurent K, Giuliano S, Larbret F, Ponzio G, Gounon P, Le Marchand-Brustel Y, Giorgetti-Peraldi S, Cormont M, Bertolotto C, et al: Targeting cancer cell metabolism: The combination of metformin and 2-deoxyglucose induces p53-dependent apoptosis in prostate cancer cells. Cancer Res 70: 2465-2475, 2010.

137. Ben Sahra I, Le Marchand-Brustel Y, Tanti JF and Bost F: Metformin in cancer therapy: A new perspective for an old antidiabetic drug? Mol Cancer Ther 9: 1092-1099, 2010.

138. Miranda VC, Braghiroli MI,Faria LD, Bariani G, Alex A, Bezerra Neto JE, Capareli FC, Sabbaga J, Lobo Dos Santos JF, Hoff PM and Riechelmann RP: Phase 2 trial of metformin combined with 5 -fluorouracil in patients with refractory metastatic colorectal cancer. Clin Colorectal Cancer 15: 321-328.e1, 2016.

139. Zhang HH and Guo XL: Combinational strategies of metformin and chemotherapy in cancers. Cancer Chemother Pharmacol 78: $13-26,2016$

140. Hosono K, Endo H, Takahashi H, Sugiyama M, Sakai E, Uchiyama T, Suzuki K, Iida H, Sakamoto Y, Yoneda K, et al: Metformin suppresses colorectal aberrant crypt foci in a short-term clinical trial. Cancer Prev Res (Phila) 3: 1077-1083, 2010.

141. Zhang Y, Guan M, Zheng Z, Zhang Q, Gao F and Xue Y: Effects of metformin on CD133+ colorectal cancer cells in diabetic patients. PLoS One 8: e81264, 2013

142. Montales MT, Simmen RC, Ferreira ES, Neves VA and Simmen FA: Metformin and soybean-derived bioactive molecules attenuate the expansion of stem cell-like epithelial subpopulation and confer apoptotic sensitivity in human colon cancer cells. Genes Nutr 10: 49,2015.

143. Zhou XZ, Xue YM, Zhu B and Sha JP: Effects of metformin on proliferation of human colon carcinoma cell line SW-480. Nan Fang Yi Ke Da Xue Xue Bao 30: 1935-1938, 1942, 2010 (In Chinese)

144. Nie Z, Zhu H and Gu M: Reduced colorectal cancer incidence in type 2 diabetic patients treated with metformin: A meta-analysis Pharm Biol 54: 2636-2642, 2016.

145. Sehdev A, Shih YC, Vekhter B, Bissonnette MB, Olopade OI and Polite BN: Metformin for primary colorectal cancer prevention in patients with diabetes: A case-control study in a US population. Cancer 121: 1071-1078, 2015.

146. Cho YH, Ko BM, Kim SH, Myung YS, Choi JH, Han JP, Hong SJ, Jeon SR, Kim HG, Kim JO and Lee MS: Does metformin affect the incidence of colonic polyps and adenomas in patients with type 2 diabetes mellitus? Intest Res 12: 139-145, 2014. 
147. Lonardo E, Cioffi M, Sancho P, Crusz S and Heeschen C: Studying pancreatic cancer stem cell characteristics for developing new treatment strategies. J Vis Exp: e52801, 2015.

148. Iliopoulos D, Hirsch HA and Struhl K: Metformin decreases the dose of chemotherapy for prolonging tumor remission in mouse xenografts involving multiple cancer cell types. Cancer Res 71: 3196-3201, 2011.

149. Hirsch HA, Iliopoulos D and Struhl K: Metformin inhibits the inflammatory response associated with cellular transformation and cancer stem cell growth. Proc Natl Acad Sci USA 110: 972-977, 2013.

150. Hirsch HA, Iliopoulos D, Tsichlis PN and Struhl K: Metformin selectively targets cancer stem cells, and acts together with chemotherapy to block tumor growth and prolong remission. Cancer Res 69: 7507-7511, 2009.

151. Vazquez-Martin A, Oliveras-Ferraros C, Cufi S, Del Barco S, Martin-Castillo B and Menendez JA: Metformin regulates breast cancer stem cell ontogeny by transcriptional regulation of the epithelial-mesenchymal transition (EMT) status. Cell Cycle 9: 3807-3814, 2010.

152. Sui X, Xu Y, Yang J, Fang Y, Lou H, Han W, Zhang M, Chen W, Wang K, Li D, et al: Use of metformin alone is not associated with survival outcomes of colorectal cancer cell but AMPK activator AICAR sensitizes anticancer effect of 5-fluorouracil through AMPK activation. PLoS One 9: e97781, 2014.

153. Burn J and Sheth $\mathrm{H}$ : The role of aspirin in preventing colorectal cancer. Br Med Bull 119: 17-24: 2016.

154. Nan H, Hutter CM, Lin Y, Jacobs EJ, Ulrich CM, White E, Baron JA, Berndt SI, Brenner H, Butterbach K, et al: Association of aspirin and NSAID use with risk of colorectal cancer according to genetic variants. JAMA 313: 1133-1142, 2015.

155. Sabatino L, Pancione M, Votino C, Colangelo T, Lupo A, Novellino E, Lavecchia A and Colantuoni V: Emerging role of the $\beta$-catenin-PPAR $\gamma$ axis in the pathogenesis of colorectal cancer. World J Gastroenterol 20: 7137-7151, 2014.

156. Dihlmann S, Siermann A and von Knebel Doeberitz M: The nonsteroidal anti-inflammatory drugs aspirin and indomethacin attenuate beta-catenin/TCF-4 signaling. Oncogene 20: 645-653, 2001.

157. Hawcroft G, D'Amico M, Albanese C, Markham AF, Pestell RG and Hull MA: Indomethacin induces differential expression of beta-catenin, gamma-catenin and T-cell factor target genes in human colorectal cancer cells. Carcinogenesis 23: 107-114, 2002.

158. Alberts SR, Sargent DJ, Nair S, Mahoney MR, Mooney M, Thibodeau SN, Smyrk TC, Sinicrope FA, Chan E, Gill S, et al: Effect of oxaliplatin, fluorouracil, and leucovorin with or without cetuximab on survival among patients with resected stage III colon cancer: A randomized trial. JAMA 307: 1383-1393, 2012

159. Cao R, Zhang S, Ma D and Hu L: A multi-center randomized phase II clinical study of bevacizumab plus irinotecan, 5-fluorouracil, and leucovorin (FOLFIRI) compared with FOLFIRI alone as second-line treatment for Chinese patients with metastatic colorectal cancer. Med Oncol 32: 325, 2015

160. Longley DB, Harkin DP and Johnston PG: 5-fluorouracil: Mechanisms of action and clinical strategies. Nat Rev Cancer 3: 330-338, 2003.

161. Yamada Y, Takahari D, Matsumoto H, Baba H, Nakamura M, Yoshida K, Yoshida M, Iwamoto S, Shimada K, Komatsu Y, et al: Leucovorin, fluorouracil, and oxaliplatin plus bevacizumab versus S-1 and oxaliplatin plus bevacizumab in patients with metastatic colorectal cancer (SOFT): An open-label, non-inferiority, randomised phase 3 trial. Lancet Oncol 14: 1278-1286, 2013.

162. Schmoll HJ, Tabernero J, Maroun J, de Braud F, Price T, Van Cutsem E, Hill M, Hoersch S, Rittweger K and Haller DG: Capecitabine plus oxaliplatin compared with fluorouracil/folinic acid as adjuvant therapy for stage iii colon cancer: Final results of the NO16968 randomized controlled phase III trial. J Clin Oncol 33: 3733-3740, 2015.

163. Élez E, Kocáková I, Höhler T, Martens UM, Bokemeyer C, Van Cutsem E, Melichar B, Smakal M, Csőszi T, Topuzov E, et al: Abituzumab combined with cetuximab plus irinotecan versus cetuximab plus irinotecan alone for patients with KRAS wild-type metastatic colorectal cancer: The randomised phase I/II POSEIDON trial. Ann Oncol 26: 132-140, 2015.
164. Sclafani F, Kim TY, Cunningham D, Kim TW, Tabernero J, Schmoll HJ, Roh JK, Kim SY, Park YS, Guren TK, et al: A randomized phase II/III study of dalotuzumab in combination with cetuximab and irinotecan in chemorefractory, KRAS wild-type, metastatic colorectal cancer. J Natl Cancer Inst 107: djv258, 2015.

165. Fujita K, Kubota Y, Ishida H and Sasaki Y: Irinotecan, a key chemotherapeutic drug for metastatic colorectal cancer. World J Gastroenterol 21: 12234-12248, 2015.

166. de Gramont A, Van Cutsem E, Schmoll HJ, Tabernero J, Clarke S, Moore MJ, Cunningham D, Cartwright TH, Hecht JR, Rivera F, et al: Bevacizumab plus oxaliplatin-based chemotherapy as adjuvant treatment for colon cancer (AVANT): A phase 3 randomised controlled trial. Lancet Oncol 13: 1225-1233, 2012.

167. Bayoglu IV, Yildiz I, Varol U, Cokmert S, Alacacioğlu A, Kucukzeybek Y, Akyol M, Demir L, Dirican A and Tarhan O: Uracil/tegafur as a possible salvage therapy in chemo-refractory colorectal cancer patients: A single institutional retrospective study. Contemp Oncol (Pozn) 19: 385-390, 2015.

168. Feng QY, Wei Y, Chen JW, Chang WJ, Ye LC, Zhu DX and Xu JM: Anti-EGFR and anti-VEGF agents: Important targeted therapies of colorectal liver metastases. World J Gastroenterol 20: 4263-4275, 2014.

169. Strickler JH and Hurwitz HI: Bevacizumab-based therapies in the first-line treatment of metastatic colorectal cancer. Oncologist 17: 513-524, 2012.

170. Roviello G, Bachelot T, Hudis CA, Curigliano G, Reynolds AR Petrioli R and Generali D: The role of bevacizumab in solid tumours: A literature based meta-analysis of randomised trials. Eur J Cancer 75: 245-258, 2017.

171. Huang J,Nair SG, Mahoney MR, Nelson GD, Shields AF, Chan E, Goldberg RM, Gill S, Kahlenberg MS, Quesenberry JT, et al: Comparison of FOLFIRI with or without cetuximab in patients with resected stage III colon cancer; NCCTG (Alliance) intergroup trial N0147. Clin Colorectal Cancer 13: 100-109, 2014.

172. Terazawa T, Nishitani H, Kato K, Hashimoto H, Akiyoshi K, Ito Y, Nakamoto A, Iwasa S, Nakajima TE, Hamaguchi T, et al: Phase II study of cetuximab with irinotecan for KRAS wild-type colorectal cancer in Japanese patients. Asia Pac J Clin Oncol 13: e132-e137, 2017.

173. Tay RY, Wong R and Hawkes EA: Treatment of metastatic colorectal cancer: Focus on panitumumab. Cancer Manag Res 7: 189-198, 2015.

174. Bahrami A, Hassanian SM, ShahidSales S, Farjami Z, Hasanzadeh M, Anvari K, Aledavood A, Maftouh M, Ferns GA, Khazaei $\mathrm{M}$ and Avan A: Targeting RAS signaling pathway as a potential therapeutic target in the treatment of colorectal cancer. J Cell Physiol: Mar 6, 2017 (Epub ahead of print).

175. Françoso A and Simioni PU: Immunotherapy for the treatment of colorectal tumors: Focus on approved and in-clinical-trial monoclonal antibodies. Drug Des Devel Ther 11: 177-184, 2017.

176. Ursem C, Van Loon K and Venook A: Adjuvant therapy trials. Cancer J 22: 196-198, 2016.

177. Botchkina G: Colon cancer stem cells-from basic to clinical application. Cancer Lett 338: 127-140, 2013.

178. Haraguchi N, Ohkuma M, Sakashita H, Matsuzaki S, Tanaka F, Mimori K, Kamohara Y, Inoue H and Mori M: CD133+CD44+ population efficiently enriches colon cancer initiating cells. Ann Surg Oncol 15: 2927-2933, 2008.

179. Zhu L, Gibson P, Currle DS, Tong Y, Richardson RJ, Bayazitov IT, Poppleton H, Zakharenko S, Ellison DW and Gilbertson RJ: Prominin 1 marks intestinal stem cells that are susceptible to neoplastic transformation. Nature 457: 603-607, 2009.

180. Botchkina IL, Rowehl RA, Rivadeneira DE, Karpeh MS Jr, Crawford H, Dufour A, Ju J, Wang Y, Leyfman Y and Botchkina GI: Phenotypic subpopulations of metastatic colon cancer stem cells: Genomic analysis. Cancer Genomics Proteomics 6: 19-29, 2009.

181. Zhou F, Mu YD, Liang J, Liu ZX, Zhou D, Ning WL, Li YZ, Ding D and Zhang JF: Aldehyde dehydrogenase 1: A specific cancer stem cell marker for human colorectal carcinoma. Mol Med Rep 11: 3894-3899, 2015. 